\title{
Equilibrium Assays Are Required to Accurately Characterize the Activity Profiles of Drugs Modulating Gq-Protein-Coupled Receptors ${ }^{\text {[ }}$
}

\author{
Sara Bdioui, Julien Verdi, Nicolas Pierre, Eric Trinquet, Thomas Roux, and Terry Kenakin \\ Cisbio Bioassays, Codolet, France (S.B., J.V., N.P., E.T., T.R.); and Department of Pharmacology, University of North Carolina \\ School of Medicine, Chapel Hill, North Carolina (T.K.)
}

Received March 25, 2018; accepted June 11, 2018

\begin{abstract}
This paper discusses the process of determining the activity of candidate molecules targeting Gq-protein activation through G-protein-coupled receptors for possible therapeutic application with two functional assays; calcium release and inositol phosphate metabolism [inositol monophosphate (IP1)]. While both are suitable for detecting ligand activity (screening), differences are seen when these assays are used to quantitatively measure ligand parameters for therapeutic activity. Specifically, responses for Gq-related pathways present different and dissimulating patterns depending on the functional assay used to assess them. To investigate the impact of functional assays on the accuracy of compound pharmacological profiles, five exemplar molecules [partial agonist, antagonist, inverse agonist, positive allosteric modulator (PAM) agonist, and positive $\beta$-PAM] targeting either muscarinic M1
\end{abstract}

or ghrelin receptors were tested using two functional assays (calcium release and IP1) and the results were compared with theoretical pharmacological models. The IP1 assay is an equilibrium assay that is able to determine the correct (i.e., internally consistent) pharmacological profiles of all tested compounds. In contrast, the nonequilibrium nature of calcium assays yields misleading classification of most of the tested compounds. Our study suggests that the use of an equilibrium assay, such as IP1, is mandatory for the optimal use of pharmacological models that can both identify mechanisms of action and also convert descriptive-to-predictive data for therapeutic systems. Such assays allow the identification of consistent and simple scales of activity that can guide medicinal chemistry in lead optimization of candidate molecules for therapeutic use.

\section{Introduction}

The process of drug lead optimization involves the characterization of the molecular profile of a drug candidate with systemindependent scales of drug activity, i.e., the profile ideally should not be linked only to the experimental system where it is observed. This is important since drugs are almost always studied and developed in test experimental systems and not the end therapeutic tissue. Therefore, a scale of activity must bridge the gap between these two systems. Pharmacologically this is done by comparing experimental data to mathematical models of drug-receptor interaction and deriving universal parameters such as equilibrium dissociation constants [equilibrium dissociation constant of the agonist-receptor complex $\left(K_{\mathrm{A}}\right)$ and equilibrium dissociation constant of antagonist (or allosteric modulator)-receptor complex $\left.\left(K_{\mathrm{B}}\right)\right]$, measures of efficacy $(\tau)$, or allosteric parameters describing effects on affinity $(\alpha)$ and efficacy $(\beta)$, which then can be used to predict agonist activity

https://doi.org/10.1124/mol.118.112573.

S This article has supplemental material available at molpharm. aspetjournals.org. in all functional systems. A corollary to this approach is that these same models often provide internal checks, whereby certain predictions must coincide with the observations to correctly ascribe drug mode of action. For this procedure to be successful, it is imperative that the assays used to determine drug function accurately reflect the molecular activity of the molecule at the receptor.

There are two fundamentally different types of assay used in drug discovery: detection of drug activity (screening) and characterization of activity (lead optimization). Detection assays should be robust and sensitive; however, they only need to reveal ligand-receptor interaction and not necessarily quantitatively correct drug parameters. In contrast, lead optimization assays must provide predictive and accurate measures of drug activity that can be used to characterize activity in therapeutic systems. The activation of Gq-proteincoupled receptors results in increases in inositol triphosphate metabolism and calcium release in cells (Berridge et al., 2003). There are two main and well-described fluorescent-based assays that can be used to monitor the activation of the $\mathrm{Gq}$ pathway. On the one hand, calcium assays measure the release

ABBREVIATIONS: ACh, acetylcholine; BQCA, benzyl quinolone carboxylic acid [1-(4-methoxybenzyl)-4-oxo-1,4-dihydroquinoline-3-carboxylic acid]; $\mathrm{CHO}$, Chinese hamster ovary; DR, dose ratio; GHSR1a, growth hormone secretagogue receptor type 1a; HEK, human embryonic kidney; HR, heart rate; IP1, inositol monophosphate; $K_{\mathrm{A}}$, equilibrium dissociation constant of the agonist-receptor complex; $K_{\mathrm{B}}$, equilibrium dissociation constant of antagonist (or allosteric modulator)-receptor complex; NECA, 5'-N-ethylcarboxamidoadenosine; PAM, positive allosteric modulator; SPA, [D-Arg ${ }^{1}$, D-Phe ${ }^{5}$, DTrp $^{7,9}{ }^{, \text {Leu }^{11}}{ }^{\text {] }}$-substance P. 
of calcium flux into the cells using permeant dyes, in which fluorescence emission increases upon binding to calcium (Chambers et al., 2003). On the other hand, the inositol monophosphate (IP1) assay measures the accumulation of IP1, which is a metabolite of inositol triphosphate, through a competition assay based on homogeneous time-resolved fluorescence technology (Trinquet et al., 2011). It will be seen that both IP1 and calcium assays function well in screening mode but differ considerably in lead optimization mode. This paper discusses whether these functional readouts deliver accurate data for ligand characterization or if they lead to dissimulating and misleading profiles.

It is well known that calcium transients emanate from hemi-equilibrium assays that do not furnish sustained agonist responses; therefore, pharmacological procedures normally requiring these, such as detecting inverse, partial, and positive allosteric modulator (PAM) agonism, are precluded. However, there are published procedures that have been used to furnish mass action pharmacological profiles for these types of ligands through coaddition formats, which apparently yield the correct profiles for some of these types of ligands. It can be shown that while these procedures apparently provide correct qualitative patterns of drug effect, they in fact can yield erroneous drug parameters that lead to misclassification of drug activity. The key to identifying such dissimulations is the application of internal checks within the mathematical models of drug receptor pharmacodynamics. These concepts are illustrated in the present paper with examples of five general types of ligands [agonists, antagonists, inverse agonists, PAM agonists, and PAMs increasing agonist efficacy ( $\beta$-PAMs)]. Specifically, the results obtained suggest that the use of an equilibrium assay based on the determination of the intracellular accumulation of IP1 provides correct pharmacological profiles, whereas nonequilibrium calcium assays provide misleading classification of drug activity.

\section{Materials and Methods}

\section{Cell Lines and Culture}

Chinese hamster ovary (CHO) cells stably expressing the muscarinic $\mathrm{M} 1$ receptor (CHO-M1) were cultured in F-12 complete medium complemented with $10 \%$ stromal vascular fraction and penicillin/ streptomycin/G418 at $37^{\circ} \mathrm{C}$ with $5 \% \mathrm{CO}_{2}$. Human embryonic kidney (HEK)293 cells stably expressing the growth hormone secretagogue receptor type 1a [(GHSR1a) HEK293-GHSR1a] were cultured in Dulbecco's modified Eagle's medium with $10 \%$ stromal vascular fraction and penicillin/streptomycin/G418 at $37^{\circ} \mathrm{C}$ with $5 \% \mathrm{CO}_{2}$.

\section{Compounds}

The following muscarinic M1 receptor ligands were used: acetylcholine (ACh) (Sigma Aldrich, Saint-Quentin Fallavier, France), alvameline (Sigma Aldrich), atropine (Sigma Aldrich), benzyl quinolone carboxylic acid [(BQCA) 1-(4-methoxybenzyl)-4-oxo-1,4-dihydroquinoline-3carboxylic acid] (Sigma Aldrich), carbachol (Sigma Aldrich), and tiotropium bromide (Tocris, Bristol, United Kingdom). The following GHSR1a receptor ligands were used: human ghrelin (Tocris) and $\left[\mathrm{D}-\mathrm{Arg}^{1}, \mathrm{D}-\mathrm{Phe}^{5}, \mathrm{DTrp}^{7,9}, \mathrm{Leu}^{11}\right]$-substance P (SPA) (Sigma Aldrich). The following adenosine receptor ligand was used: $5^{\prime}$ $\mathrm{N}$-ethylcarboxamidoadenosine (NECA) (Tocris).

\section{Cell Plate Preparation}

Cells were dissociated from the flask when they reached $80 \%$ confluence, and then spun and resuspended in the appropriate complemented culture medium at the desired concentration. Cells were seeded into 96-well culture-treated plates for IP1 and calcium experiments (Greiner Bio-One, Courtabœuf, France) at $100 \mu \mathrm{l} /$ well and incubated overnight at $37^{\circ} \mathrm{C}$ with $5 \% \mathrm{CO}_{2}$ before being used in functional assays.

\section{Measurement of the Intracellular Accumulation of IP1}

The homogeneous time-resolved fluorescence IP-One-Gq assay (IP1) was used to measure intracellular IP1 accumulation according to the manufacturer's instructions (Cisbio Bioassays, Codolet, France). In brief, on the day of the experiment, serial dilutions of compounds were prepared in the stimulation buffer of the kit (containing $50 \mathrm{mM} \mathrm{LiCl}$ to prevent IP1 degradation) at the desired working concentration. Cell culture medium supernatant was removed from the plates. After a washing step with phosphate-buffered saline, cells were treated by addition of $70 \mu \mathrm{l} / \mathrm{well}$ of the different compounds and incubated for the indicated time at $37^{\circ} \mathrm{C}, 5 \% \mathrm{CO}_{2}$. Then, IP1 detection was allowed by addition of the detection reagents previously diluted in the appropriate kit lysis and detection buffer ( $30 \mu \mathrm{l}$ total). Plates were incubated for 1 hour at room temperature and the homogeneous time-resolved fluorescence signal was recorded using a PHERAstar FS reader (BMG LABTECH, Ortenberg, Germany) with flash lamp excitation.

Assay parameters, such as the cellular density required to work within the assay dynamic range or the determination of the appropriate stimulation time for each compound (i.e., ACh, Alvameline, Atropine), were properly optimized with the cellular models used (CHO-M1 and HEK293-GHSR1a).

\section{Measurement of Calcium}

After cell culture medium removal, cells were washed once with phosphate-buffered saline and incubated for 1 hour at $37^{\circ} \mathrm{C}, 5 \% \mathrm{CO}_{2}$ with $2 \mu \mathrm{M}$ of Fluo-4 AM (ThermoFisher Scientific, Villebon sur Yvette, France) previously diluted in Hanks' balanced salt solution (ThermoFisher Scientific) containing $20 \mathrm{mM}$ HEPES, $3.3 \mathrm{mM} \mathrm{Na}_{2} \mathrm{CO}_{3}, 1.3 \mathrm{mM}$ $\mathrm{CaCl}_{2}, 1 \mathrm{mM} \mathrm{MgSO}_{4}, 2.5 \mathrm{mM}$ probenecid, $0.1 \%$ bovine serum albumin, pH7.4 (assay buffer). After dye removal, cells were washed once with the assay buffer. Then, after addition of $50 \mu \mathrm{l} /$ well of assay buffer, cells were treated by addition of $50 \mu \mathrm{l} /$ well of the different compounds diluted in the assay buffer and the $\mathrm{Ca}^{2+}$ release was measured with a FlexStation 3 reader (Molecular Devices, Workingham, United Kingdom). Prior to use, the cellular density as well as the Fluo-4 AM concentration to work in nonsaturated conditions were properly optimized with the different cellular models (CHO-M1 and HEK293GHSR1a).

\section{Cells Treatment With Compounds}

\section{Compound Screening Protocols.}

Agonist screening mode. In the IP1 assay, $10 \mu \mathrm{M}$ of compounds were incubated 60 minutes prior to signal detection while the $\mathrm{Ca}^{2+}$ flux was directly recorded upon compound addition in the calcium assay. To observe antagonism, a selected concentration around the $\mathrm{EC}_{80}$ values of full agonists (ACh for CHO-M1 cells and ghrelin for HEK-GHSR1a cells) were used. For the IP1 assay, compounds at $10 \mu \mathrm{M}$ were preincubated 30 minutes before agonist addition, followed by an additional 30 minutes of incubation prior to detection. For the calcium assay, the same compounds were preincubated 60 minutes before agonist addition in pre-equilibration format or added together with the agonist for coaddition format; and calcium release was directly recorded upon agonist addition.

PAM screening mode. To observe the response enhancement induced by the PAM in CHO-M1 cells, a selected concentration of ACh around the $\mathrm{EC}_{30}$ value was used. For the IP1 assay, compounds at $10 \mu \mathrm{M}$ were preincubated 30 minutes before agonist addition, followed by an additional 30 minutes of incubation prior to detection. For the calcium assay, the same compounds were preincubated 60 minutes before agonist addition in pre-equilibration format or added together 
with the agonist for coaddition format; and calcium release was directly recorded upon agonist addition.

Compound Pharmacological Characterization Protocols. Two modes of drug addition were used in the calcium assay when two ligands were involved (i.e., partial agonist and antagonist or PAM and full agonist). The first mode involved preincubation with one of the two ligands before addition of the other (pre-equilibrium format); e.g., the partial agonist was added for a given period of time before addition of a full agonist. This preincubation format was used both for the IP1 and calcium assays. In the second mode, the two ligands were added simultaneously (coaddition format). This mode was restricted to the calcium assay.

\section{Measuring Agonism}

Agonism is quantified by fitting concentration-response data to the Black-Leff operational model (Black and Leff, 1983):

$$
\text { Response }=\frac{[\mathrm{A}]^{n} \tau_{\mathrm{A}}^{n} E_{\mathrm{m}}}{[\mathrm{A}]^{n} \tau_{\mathrm{A}}^{n}+\left([\mathrm{A}]+K_{\mathrm{A}}\right)^{n}}
$$

where $[\mathrm{A}]$ is the concentration of the agonist; $K_{\mathrm{A}}$ is the equilibrium dissociation constant of the agonist-receptor complex; $E_{\mathrm{m}}$ is the maximal response window of the system; $\tau_{\mathrm{A}}$ is the efficacy of the agonist; and $n$ is the slope of the concentration-response curve. For the partial agonist alvameline, an internal check for the goodness of fit of the data to the partial agonist model was obtained by comparison of the agonist $\mathrm{EC}_{50}$ value for agonism and the $\mathrm{p} K_{\mathrm{B}}$ for antagonism. Specifically, the magnitude of the $\mathrm{EC}_{50}$ value for a partial agonist $[\mathrm{B}]$ theoretically should approximate the equilibrium dissociation constant of the ligand-receptor complex $\left(K_{\mathrm{B}}\right)$ as denoted by the relation (Black et al., 1985):

$$
\mathrm{EC}_{50}=K_{\mathrm{B}} /\left(1+\tau_{\mathrm{B}}\right)
$$

where $\tau_{\mathrm{B}}$ is the efficacy of the partial agonist. In the case of low-efficacy partial agonists $(\tau \rightarrow 0)$, the $\mathrm{EC}_{50}$ value closely approximates the $K_{\mathrm{B}}$ value.

\section{Measuring Antagonism}

Antagonism is quantified by obtaining concentration-response curves to a full agonist, in this case $\mathrm{ACh}$, in the absence and presence of a range of concentrations of the partial agonist alvameline. The ratios of concentrations of $\mathrm{ACh}$ producing $50 \%$ maximal response for antagonists and inverse agonists and $75 \%$ maximal response for the partial agonist alvameline, in which each curve is used to calculate equiactive dose ratios (DRs) for $\mathrm{ACh}$, are used in the Schild equation (Arunlakshana and Schild, 1959):

$$
\log (\mathrm{DR}-1)=n \log [\mathrm{B}]-\mathrm{p} K_{\mathrm{B}}
$$

where $[\mathrm{B}]$ is the concentration of partial agonist, and $n$ is the slope of the regression and $\mathrm{p} K_{\mathrm{B}}$ (the $-\log K_{\mathrm{B}}$, where $K_{\mathrm{B}}$ is the equilibrium dissociation constant of the partial agonist-receptor complex).

\section{Simulating Effects of Coaddition of Fast and Slow Ligands}

Simulations for the effect of coaddition of full and partial agonists (acetylcholine and alvameline) were carried out for two ligands utilizing kinetic equations, published by Motulsky and Mahan (1984), to calculate receptor occupancy in real time. Specifically, the receptor occupancy for the full agonist $\left(\rho_{\mathrm{A}}\right)$ having onset and offset rates of $k_{1}$ and $k_{2}$, respectively, added simultaneously with a partial agonist having on and off rates of $k_{3}$ and $k_{4}$, respectively, is given by Motulsky and Mahan (1984):

$$
\rho_{\mathrm{A}}=\frac{k_{1}[\mathrm{~A}]}{\Omega-\psi}\left(\frac{k_{4}(\Omega-\psi)}{\Omega \psi}+\frac{k_{4}-\Omega}{\Omega} e^{-\Omega t}-\frac{k_{4}-\psi}{\psi} e^{-\psi t}\right)
$$

where

$$
\begin{aligned}
& \Omega=0.5\left\{K_{\mathrm{A}}+K_{\mathrm{B}}+\sqrt{\left(K_{\mathrm{A}}-K_{\mathrm{B}}\right)^{2}+4 k_{1} k_{3}[\mathrm{~A}][\mathrm{B}]}\right\} \\
& \Psi=0.5\left\{K_{\mathrm{A}}+K_{\mathrm{B}}-\sqrt{\left(K_{\mathrm{A}}-K_{\mathrm{B}}\right)^{2}+4 k_{1} k_{3}[\mathrm{~A}][\mathrm{B}]}\right\}
\end{aligned}
$$

and

$$
\begin{aligned}
& K_{\mathrm{A}}=k_{1}[\mathrm{~A}]+k_{2} \\
& K_{\mathrm{B}}=k_{3}[\mathrm{~B}]+k_{4}
\end{aligned}
$$

The agonist response is then calculated from the Black-Leff operational model (eq. 1) through the transform $[\mathrm{A}] / K_{\mathrm{A}}=\rho_{\mathrm{A}} /\left(1-\rho_{\mathrm{A}}\right)$.

\section{Measuring Inverse Agonism}

Inverse agonism is measured as the depression of functional basal response to the inverse agonist; the effect can be quantified through an $\mathrm{EC}_{50}$ value from the concentration-response curve. Since inverse agonists are antagonists of the effects of highefficacy agonists, the affinity of inverse agonists also can be measured through Schild analysis (see eq. 2). An internal check of the parameters measured with the Schild and inverse agonism assays is obtained through the comparison of the $\mathrm{p} K_{\mathrm{B}}$ and the $\mathrm{pEC}_{50}$ for inverse agonism. Specifically, the constitutive response of the receptor system is given by

$$
\text { Constitutive activity }=\frac{\beta L \tau_{\mathrm{R}}[\mathrm{B}] / K_{\mathrm{B}}+L \tau_{\mathrm{R}}}{[\mathrm{B}] / K_{\mathrm{B}}\left[1+\beta L\left(1+\tau_{\mathrm{R}}\right)\right]+L\left(\tau_{\mathrm{R}}+1\right)+1}
$$

where $\lambda$ is the ratio of affinity of the inverse agonist for the active versus the inactive receptor state (Kenakin, 2014); for inverse agonists by definition $\lambda<<1$. From eq. 9 the expression for the $\mathrm{EC}_{50}$ value for inverse agonism is given by

$$
\mathrm{EC}_{50}=\frac{K_{\mathrm{B}}\left[L\left(\tau_{R}+1\right)+1\right]}{\lambda L\left(\tau_{R}+1\right)+1}
$$

For all inverse agonists where $\lambda<1$, eq. 10 predicts that the $\mathrm{EC}_{50}$ value will always be mathematically greater than the $K_{\mathrm{B}}$ value; this functions as an internal check for mass action inverse agonism.

\section{PAM Agonists}

The model describing functional allosteric effects is an amalgam of the Stockton-Ehlert allosteric receptor binding model (Stockton et al., 1983; Ehlert, 1988) and the Black-Leff operational model for agonism (Black and Leff, 1983). This model yields the equation for the response to an agonist [A] in the presence of a given concentration of a modulator [B] as follows (Ehlert, 2005; Kenakin, 2005; Price et al., 2005):

Response $=\frac{\tau_{\mathrm{A}}[\mathrm{A}] / K_{\mathrm{A}}\left(1+\alpha \beta[\mathrm{B}] / K_{\mathrm{B}}\right)+\tau_{\mathrm{B}}[\mathrm{B}] / K_{\mathrm{B}}}{[\mathrm{A}] / K_{\mathrm{A}}\left(1+\alpha[\mathrm{B}] / K_{\mathrm{B}}\right)+\tau_{\mathrm{A}}\left(1+\alpha \beta[\mathrm{B}] / K_{\mathrm{B}}\right)+[\mathrm{B}] / K_{\mathrm{B}}\left(1+\tau_{\mathrm{B}}\right)+1}$

where $K_{\mathrm{A}}$ and $K_{\mathrm{B}}$ are the equilibrium dissociation constants of the agonist and modulator receptor complexes, respectively; $\tau_{\mathrm{A}}$ and $\tau_{\mathrm{B}}$ are the respective efficacies of the agonist and modulator; $\alpha$ is the effect of the modulator on agonist affinity for the receptor (and reciprocally the effect of the agonist on the affinity of the modulator); and $\beta$ is the effect of the modulator on the efficacy of the agonist (and reciprocally the effect of the agonist on the efficacy of the modulator). The allosteric modulator BQCA is characterized by comparison of experimental concentration-response curves to acetylcholine or alvameline in the absence and presence of various concentrations of BQCA and subsequent estimation of the parameters $\tau_{\mathrm{B}}, \alpha, \beta$, and $K_{\mathrm{B}}$ for BQCA. 
A

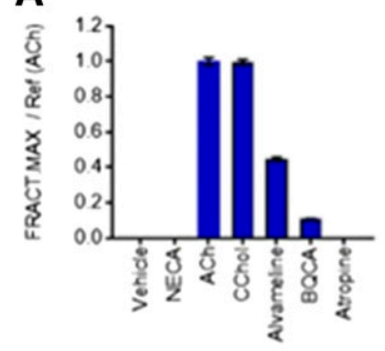

C

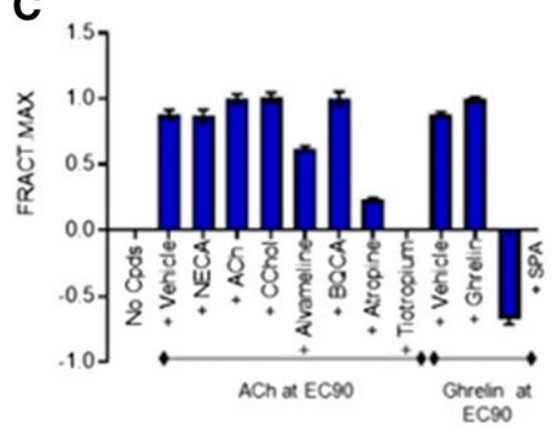

F

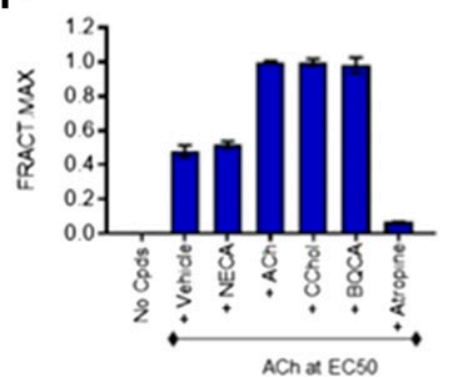

B

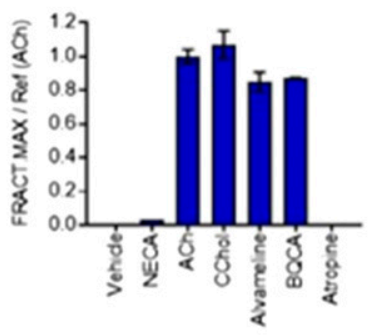

D

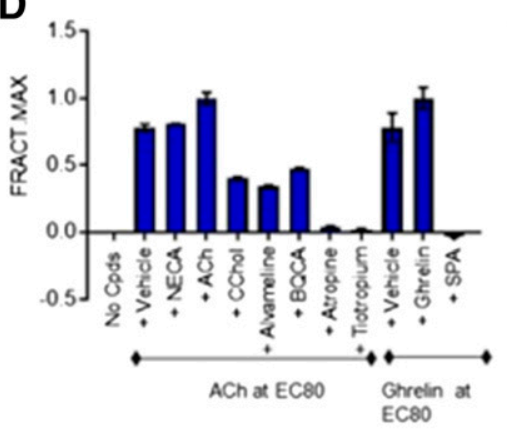

E
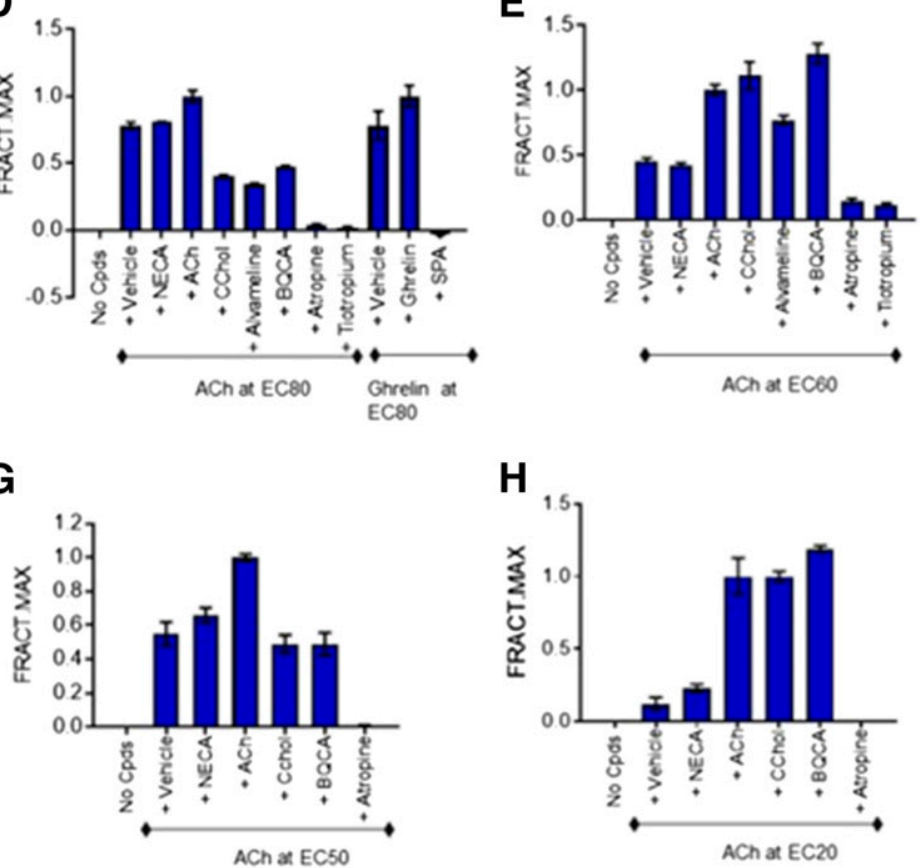

H

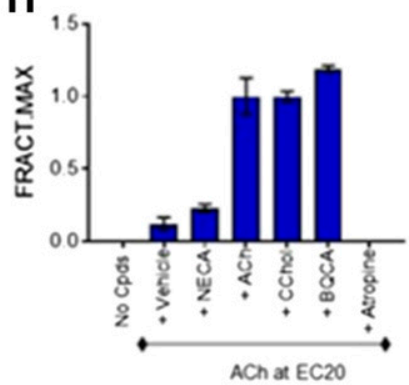

Fig. 1. Effects of single concentrations of test compounds targeting the muscarinic M1 (CHO-M1 stable cell line) or the ghrelin (HEK293-GHSR1a stable cell line) receptors in various screening formats. For the muscarinic M1 receptor, the compounds used for screening are: full agonists, ACh and carbachol (CChol); partial agonist, alvameline; antagonists, atropine and tiotropium; PAM agonist, BQCA; irrelevant compound, NECA; and vehicle condition, buffer replacing tested compounds. For the ghrelin receptor, the compounds used for the screening are: full agonist, ghrelin; inverse agonist, SPA; and vehicle condition, buffer replacing tested compounds. Agonists screening format: (A) IP1 responses to addition of various compounds at $10 \mu \mathrm{M}$ and 60-minute equilibration and (B) effects of the same ligands in the calcium assay. Antagonists screening format: (C) IP1 response to various compounds at $10 \mu \mathrm{M}$, pre-equilibrated 30 minutes before addition of $\mathrm{EC}_{90}$ of $\mathrm{ACh}$ or ghrelin followed by 30 -minute equilibration prior detection; (D) effect of the same ligands in the calcium assay, pre-equilibrated 60 minutes before addition of $\mathrm{EC}_{80}$ of $\mathrm{ACh}$ or ghrelin and direct detection; and (E) effect of the same ligands in the calcium assay coadded with $\mathrm{ACh}$ at $\mathrm{EC}_{60}$ with direct detection. PAM screening format: (F) IP1 response to various compounds at $10 \mu \mathrm{M}$, preequilibrated 30 minutes before addition of $\mathrm{EC}_{50}$ of $\mathrm{ACh}$ or ghrelin followed by 30 -minute equilibration prior detection; $(\mathrm{G})$ effect of the same ligands in the calcium assay, pre-equilibrated 60 minutes before addition of $\mathrm{EC}_{50}$ of $\mathrm{ACh}$ or ghrelin and direct detection; and $(\mathrm{H})$ effect of the same ligands in the calcium assay coadded with $\mathrm{ACh}$ at $\mathrm{EC}_{20}$ with direct detection.

\section{Results}

Single Concentration Screening. Figure 1 shows data for single concentration testing of various types of molecules in IP1 and calcium assays. At this point it is useful to describe the two formats that have been employed for calcium transient measurement. The first is a pre-equilibration format that adds a test compound at time zero to allow the test compound to equilibrate with receptors for a period of time and then challenges with a second compound, a reference full agonist (to gauge the effect of the previously added compound), after the period of equilibration. A second format is where both compounds are added simultaneously, and a single reading of response taken immediately (coaddition format). The fact that the calcium response is transient defines which of these types of formats are optimal for calcium responses.

There are four basic types of screens used in drug discovery. These are designed to detect: 1) agonists, 2) antagonists, 3) inverse agonists (constitutive screening and orphans), and 4) allosteric modulators. The panels in Fig. 1 reveal the behavior of exemplar molecules in these classes in IP1 versus calcium assays. The direct effects of molecules in IP1 and calcium assays (where calcium response is measured immediately after addition of compound) are shown in the agonist format. The requirements of an agonist assay are robustness, low variability, and high sensitivity to low-efficacy activation. As seen in Fig. 1A, the IP1 assay shows acetylcholine and carbachol to be full agonists, alvameline to be a partial agonist, atropine (an antagonist) to show no efficacy, an unrelated ligand for another receptor (NECA) to show no activity, and a low-efficacy PAM agonist (BQCA) to show low, positive agonist response. The data for calcium (Fig. 1B) show comparable effects for positive agonism.

Figure 1, C-E, shows the effects of exemplar compounds in an antagonist screen format [measurement of changes 


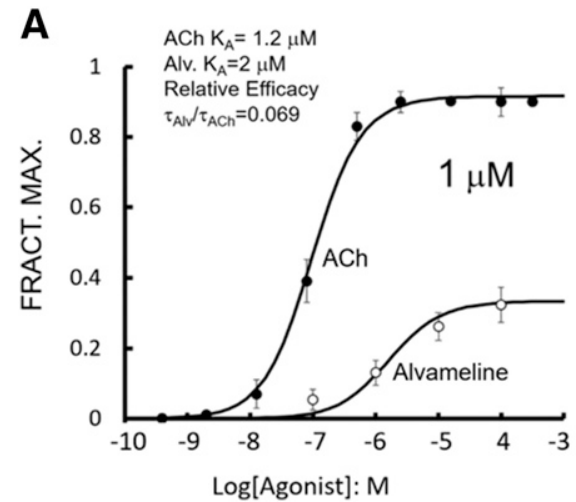

Fig. 2. Effects of ACh and alvameline on CHO-M1 cells. Ordinates as fractions of maximal response to $\mathrm{ACh}$; abscissae as logarithms of molar concentrations of agonist. Doseresponse curves of $\mathrm{ACh}$ (filled circles) and alvameline (open circles) using the IP1 assay (A) or the calcium assay (B). Data from representative experiments are shown $(n \geq 4)$. Error bars represent S.D. produced by compounds on the effect of a concentration of agonist that produces a substantial (i.e., 80\%-90\%) agonist effect] and then determination of the effect of the test compound on the elevated agonism. The IP1 format (Fig. 1C) shows the agonist response of acetylcholine and carbachol, lack of antagonism by an unrelated ligand (NECA), and blockade by the partial agonist alvameline and the competitive antagonists atropine and tiotropium. The effects of the PAM agonist BQCA indicate no antagonism. The ghrelin inverse agonist SPA produces blockade of the ghrelin response as well [as a depression of the elevated basal response (inverse agonism) in the ghrelin active IP1 assay due to constitutively active receptors]. The IP1 assay displays a similar pattern whatever the protocol used (pre-equilibration and coaddition formats) (data not shown). For calcium, the two formats of preequilibration versus coaddition are compared. For calcium responses in the pre-equilibration format (Fig. 1D), the blockade by alvameline, atropine, and tiotropium are evident as well as the lack of effect of NECA. Interestingly, the PAM agonist BQCA and full agonist carbachol present as antagonists. This is most likely due to the hemi-equilibrium nature of the calcium transient assay and also possible desensitization of the response after the first agonist effect (Kenakin et al., 2006). The antagonism by the ghrelin receptor inverse agonist SPA differs in IP1 versus calcium assays in that the inverse agonism (negative efficacy) of SPA is shown in IP1 assays but is not evident in calcium assays. In fact, this molecule presents as a simple antagonist in the pre-equilibration calcium format. In the coaddition format (Fig. 1E), the antagonist effect of alvameline, atropine, and tiotropium and potentiation effect of BQCA are consistent.

In the allosteric ligand detection mode, the assay is conducted in a chemical context, namely, in the presence of a submaximal (usually producing between $20 \%$ and $40 \%$ maximal response) agonist concentration. This allows the detection of potentiating or antagonizing effects of the test compound on the ambient agonist response in the system. Figure 1F shows that the IP1 assay correctly reveals the known positive allosteric effects of the PAM agonist BQCA and shows no effect of the unrelated ligand NECA. In the preequilibration format, the calcium assay fails to show the positive allosteric effects of BQCA but in fact indicates this molecule is an antagonist (Fig. 1G). In contrast, the coaddition format for calcium does show the positive allosteric effects of BQCA (Fig. 1H). In general, the one-shot screening format data show that, with the exception of inverse agonism and pre-equilibration in the calcium assay, both assay formats function comparably as detection assays for new molecules.

Characterization of Agonist Effect for Full and Partial Agonists. The effects of the muscarinic full agonist $\mathrm{ACh}$ and partial agonist alvameline (Watt et al., 2011) were measured in functional assays utilizing $\mathrm{CHO}$ cells expressing muscarinic M1 receptors. As seen in Fig. 2A, both acetylcholine and alvameline produce agonist effects increasing IP1 turnover; alvameline has an intrinsic activity of 0.36 consistent with partial agonist activity in this preparation. The intrinsic efficacy of alvameline, relative to that of acetylcholine, can be estimated through fitting the data in Fig. 2A using eq. 1 based on the Black-Leff model. With global constants $n$ and $E_{\mathrm{m}}$, the values for acetylcholine and alvameline are $K_{\mathrm{A}(\mathrm{ACh})}=1.2 \mu \mathrm{M}, K_{\mathrm{A}(\text { alvameline })}=2.0 \mu \mathrm{M}$, and relative efficacy $\tau_{\text {(alvameline) }} / \tau_{(\mathrm{ACh})}=0.069$.

In calcium assays, alvameline also shows partial agonist activity (intrinsic activity $=0.78)($ Fig. $2 \mathrm{~B})$ with a $\mathrm{pEC}_{50}$ value of 7.0. As seen in Fig. 2B, the calcium assay is considerably more sensitive than the IP1 assay, causing a sinistral shift of the ACh concentration-response curve and increased intrinsic activity (maximal response) for alvameline. Fitting of the Black-Leff model to these data furnishes very different values for both $K_{\mathrm{A} \text { (alvameline) }}$ and the relative efficacy of alvameline and ACh. Specifically, a substantially lower $K_{\mathrm{A} \text { (alvameline) }}$ is required to fit the calcium agonism $(0.25 \mu \mathrm{M})$ and the estimated relative efficacy is considerably lower as well (relative efficacy $\left.=\tau_{(\text {alvameline })} / \tau_{(\mathrm{ACh})}=0.0036\right)$. It should be noted that the increased absolute potency of the agonists in the calcium assay (due to larger receptor reserve or receptor coupling) will not affect the relative efficacy of acetylcholine and alvameline since the ratio cancels changes in system sensitivity. The effect of system equilibrium on agonist response should be considered at this point to assess the veracity of agonist responses produced by these two types of assay.

Accurate measurements of drug activity cannot be made without complete binding of the drug to the receptor, and sufficient time in the form of a pre-equilibration period must be allowed for this to occur (Paton and Rang, 1965). Measurement of response before complete receptor occupancy can result in underestimations of the potencies of both agonist and competitive antagonists (Kenakin, 1980). However, for assays that continuously report response in real time (such as the IP1 assay), this problem is circumvented by allowing adequate equilibration time with the agonist, i.e., for example, as seen with the slow onset dopamine agonist bifeprunox (Klein 
A

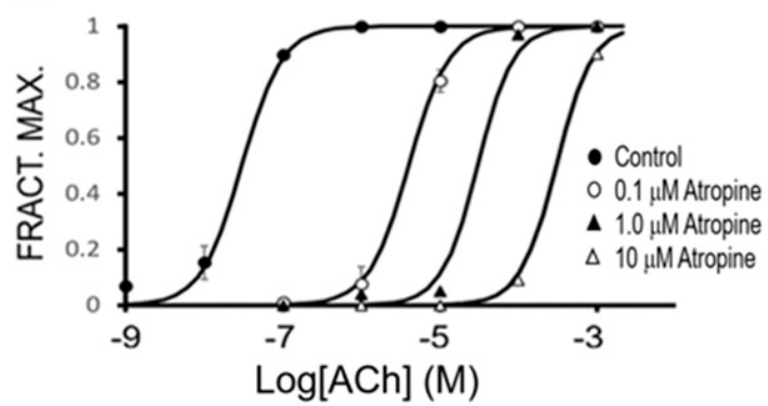

B

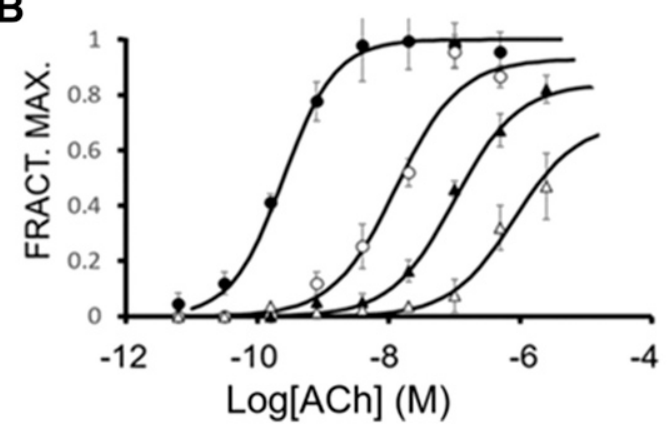

C

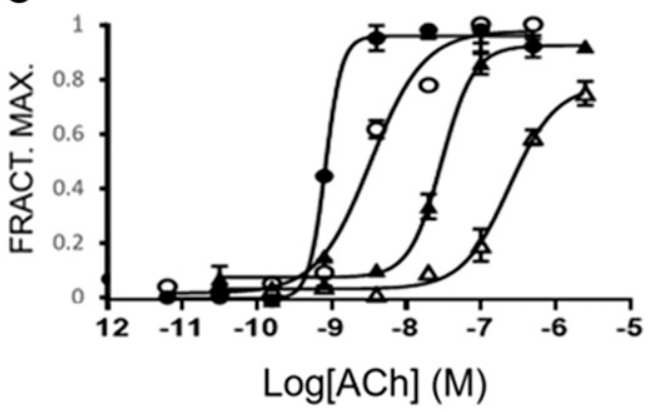

D

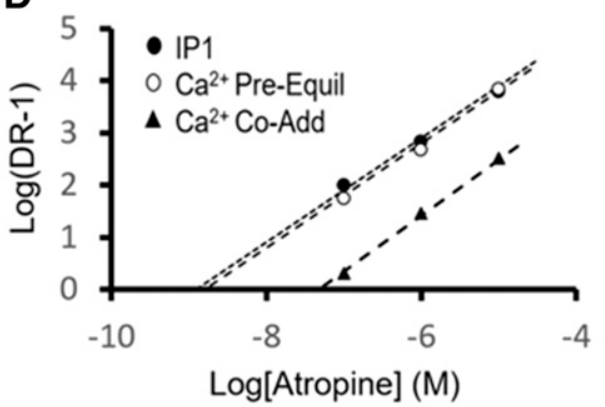

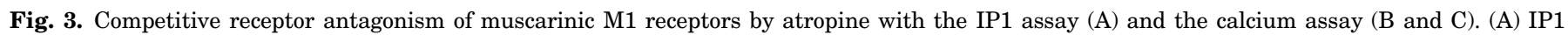

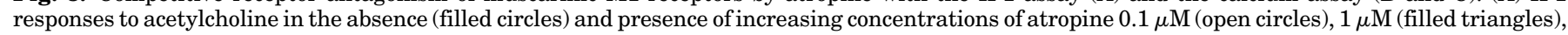

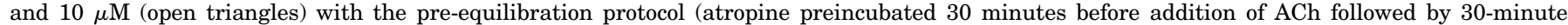

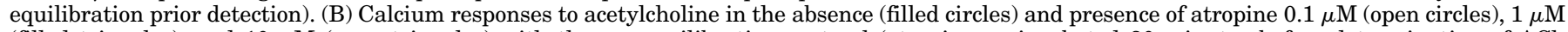

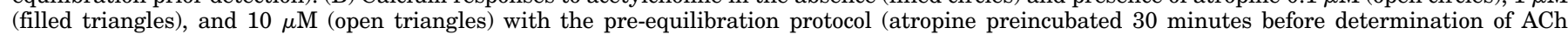

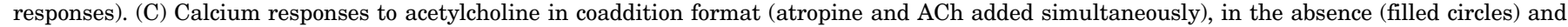

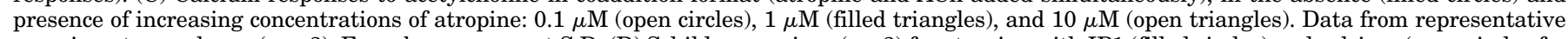

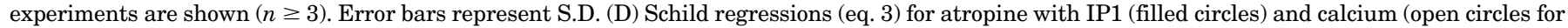
pre-equilibration format, and filled triangles in coaddition format); abscissae intercepts are the estimated $\mathrm{p} K_{\mathrm{B}}(9.0)$.

Herenbrink et al., 2016). In contrast, in a transient response assay such as calcium the window for response collection is truncated by the assay itself; therefore, increasing equilibration time does nothing to correct incomplete receptor occupancy effects (Charlton and Vauquelin, 2010). This can lead to differences in the measurement of the relative potency of agonists of differing rates of onset to the receptor with these two types of functional assay. For example, as shown by Unett et al. (2013), calcium assays underestimate the potency of a slow onset 5-hydroxytryptamine agonist dihydroergotamine by a factor of 100 when compared with inositol phosphate turnover while, in the same study, a set of fast acting 5-hydroxytryptamine agonists are well correlated between the two methods.

A relevant factor in the measurement of agonist response in calcium assays is the effect of response fade on peak height. This is explored in the simulations shown in Supplemental Fig. 1, where it can be seen that the transient nature of calcium response may indeed affect the magnitude of response in the calcium assay. The fact that the calcium response is transient, i.e., the window for gathering of receptor response closes due to the nature of the signal, is a limitation not shared with the IP1 assays (Trinquet et al., 2006, 2011). To overcome any possible kinetic effect of this nature in our study, compounds (alvameline, atropine, SPA, and BQCA) were preincubated in the pre-equilibration format for at least 30 minutes before determination of an agonist response. Experimental testing of the correspondence of indices of agonism produced by these two assays (namely, $\mathrm{EC}_{50}$ and maximal response) with independent measures of receptor occupancy were then obtained through antagonist studies (vide infra).

Characterization of Antagonist Effect of Antagonists and Partial Agonists. Antagonist is a major class of experimental drug; as seen in Fig. 1, either IP1 or calcium formats are suitable for detection of this type of activity. However, follow-up studies on these ligands essentially dictate the mechanism of action and behavior of the antagonists and this is determined in lead optimization studies. Once antagonism is detected, the effects of the putative antagonist on agonist concentration-response curves reveal the mode of action and potency. In this regard, both IP1 and calcium formats are useful. Figure 3A shows the effects of the antagonist atropine on concentration-response curves to acetylcholine production of IP1. The dextral displacement of these curves furnish DRs for use in the Schild equation (eq. 3); the resulting Schild regression yields a $\mathrm{p} K_{\mathrm{B}}$ value of 9.0 with a linear regression of slope unity indicating simple competitive antagonism (Fig. 3D). A comparable potency for atropine $\left(\mathrm{p} K_{\mathrm{B}}=9.0\right)$ is shown in calcium (pre-equilibration format) (Fig. 3B) but with the provision that the maximal responses show a concentration-dependent depression. This is a well-known effect of the hemi-equilibrium kinetics operative in calcium assays (i.e., see Kenakin et al. (2006), Charlton and Vauquelin (2010), Kenakin (2014)). With the coaddition format, the potency of atropine is significantly underestimated (Fig. 3C), most likely due to the fact that there is insufficient time with this format for the antagonist to properly equilibrate with the 
A

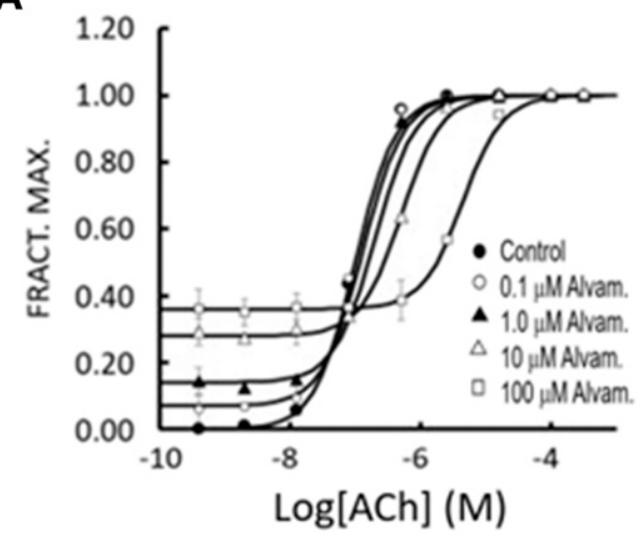

C

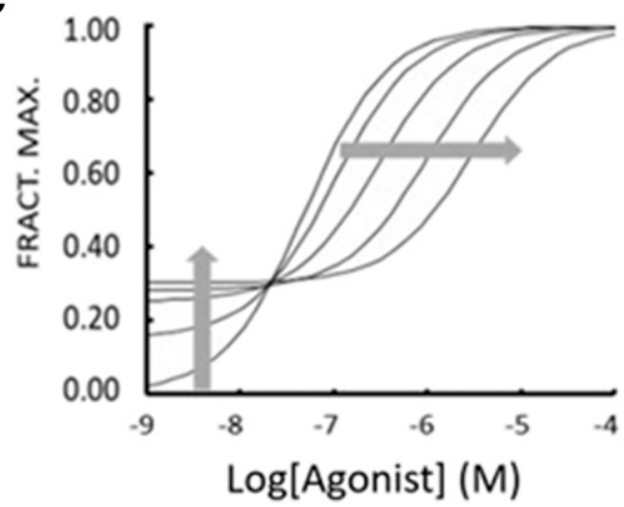

B

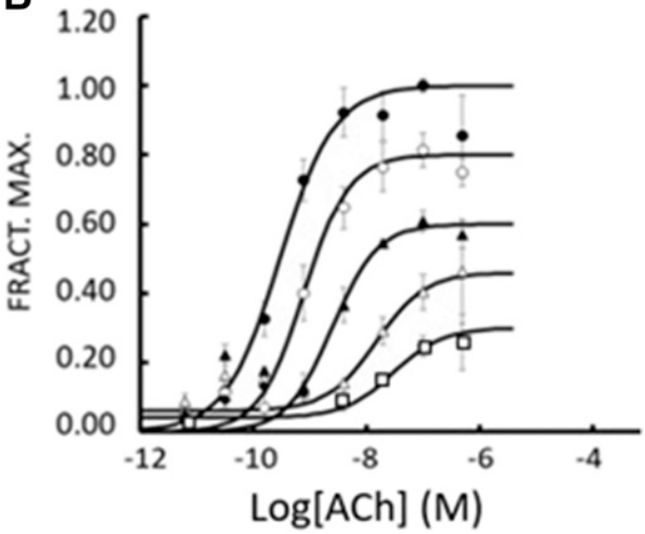

D

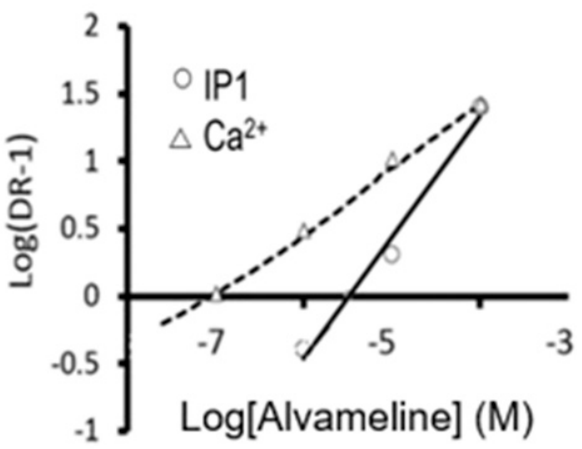

Fig. 4. Effects of various concentrations of the partial agonist alvameline on ACh responses in CHO-M1 cells in pre-equilibration format (alvameline added 60 minutes before determination of ACh responses). (A) IP1 assay: ACh responses in the absence (filled circles) and presence of increasing concentrations of alvameline: $0.1 \mu \mathrm{M}$ (open circles), $1 \mu \mathrm{M}$ (filled triangles), $10 \mu \mathrm{M}$ (open triangles), and $100 \mu \mathrm{M}$ (open squares). (B) Calcium assay: ACh responses in the absence (filled circles) or presence of increasing concentrations of alvameline: $0.1 \mu \mathrm{M}$ (open circles), $1 \mu \mathrm{M}$ (filled triangles), $10 \mu \mathrm{M}$ (open triangles), and $100 \mu \mathrm{M}$ (open squares). (C) Theoretically predicted dose-response curves of a full agonist in the presence of increasing concentrations of a partial agonist. (D) Schild regression obtained (eq. 3) utilizing the data from the IP1 assay (solid line) for the alvameline antagonism of the ACh responses. Slope of regression $=0.92 \pm 0.03,95 \%$ confidence limit $(\mathrm{c} .1)=.0.79-1.05, \mathrm{p} K_{\mathrm{B}}=5.5 \pm 0.027$, and $95 \%$ c.l. $=5.39-5.6$. Broken line shows the same regression using data from the calcium assay: slope $=0.47$. Data from representative experiments are shown $(n \geq 3)$. Error bars represent S.D. Abscissae values refer to molar concentrations.

receptors. This results in a shift to the right of the atropine Schild regression with $\mathrm{p} K_{\mathrm{B}}=7.2$ (Fig. $\left.3 \mathrm{D}\right)$. In summary, with the pre-equilibration format, both IP1 and calcium assays characterize atropine as a competitive antagonist with consistent potency. The coaddition format with the calcium assay reveals atropine as a neutral antagonist but gives erroneous potency data.

The antagonist effects of partial agonists also can be extremely useful in the characterization of these molecules. The antagonism of muscarinic receptor responses to $\mathrm{ACh}$ and alvameline was evaluated with the two assay formats to provide indices that were then used to evaluate the agonist parameters obtained from the Black-Leff operational model fitting. In general, the verisimilitude of data patterns to prediction of mathematical models provides internal checks of agonist patterns of response. For instance, while partial agonism is defined by a maximal response that is lower than the maximal response of a more efficacious full agonist in the system, it also predicts that the partial agonist will block the effects of the higher efficacy agonist, i.e., partial agonists have a dual nature of agonism and antagonism. As an example, this is shown with the $\beta$-adrenoceptor partial agonist chloropractolol, which produces $40 \%$ maximal response in rat atria (compared with the full agonist isoproterenol) but also blocks isoproterenol competitively with a $\mathrm{p} K_{\mathrm{B}}$ of 8.0 (Kenakin and Black, 1978). The dual agonism and antagonism seen in vitro reflects what is seen with these types of agonists in vivo. For instance, the partial agonist pindolol produces increases in the heart rate $(\mathrm{HR})$ in anesthetized animals with low resting HRs (chloralose-pentobarbital anesthesia, $\mathrm{HR}=132 \pm 5$ beats per minute) but reductions in the HR in anesthetized animals with high resting $\mathrm{HRs}$ (urethane anesthesia, $\mathrm{HR}=169 \pm 6$ beats per minute) (Kenakin and Johnson, 1985).

The antagonism of ACh responses by alvameline produced in the IP1 assay seen in Fig. 4A furnished DRs to yield a Schild regression that is consistent with simple competitive antagonism (slope $=0.92$ ), showing a $\mathrm{p} K_{\mathrm{B}}$ value for alvameline of 5.5 (see the Schild regression in Fig. 4D). The pattern of partial agonist effect on full agonist responses is consistent with the mass action model for partial agonism as shown in Fig. 4C. Specifically, the classic competitive model of competitive antagonism predicts that a partial agonist will elevate baseline response in accordance with its direct efficacy and shift full agonist concentration-response curves to the right (see Fig. 4C). In addition, these data are internally consistent with the agonism data, which yielded comparable affinity with 
a $\mathrm{pEC}_{50}$ value of 5.6 (Fig. $2 \mathrm{~A}$ ) as well as the $K_{\mathrm{A} \text { (alvameline) }}$ value from the analysis of alvameline agonism in the IP1 assay seen with the operational model $\left(\mathrm{p} K_{\mathrm{A}}=5.7\right)$ (Fig. 4A).

As expected, using the calcium assay in the pre-equilibration mode, alvameline does not produce the classic partial agonist profile for antagonism of responses to ACh (Fig. 4B), in that alvameline does not produce sustained agonism over the period of pre-equilibration but does produce concentrationdependent antagonism of ACh responses. At low doses of acetylcholine no elevated baseline is observed, but rather an apparent noncompetitive blockade of ACh responses is seen. This is consistent with the known hemi-equilibrium behavior of calcium transient assays and possible receptor desensitization (Charlton and Vauquelin, 2010). In fact, antagonism data from the calcium assay (pre-equilibration format) produces an aberrant Schild plot with a slope of 0.47 and negative logarithm of the concentration of antagonist producing a 2-fold shift to the right of the agonist dose-response curve ( $\mathrm{p} A_{2}$ of 7.0 ), i.e., a surrogate estimate for $\mathrm{p} K_{\mathrm{B}}$ in Schild regressions with an aberrant slope (Fig. 4D). In terms of an internal check for the agonist profile for alvameline from Fig. 2, the $\mathrm{pEC}_{50}$ value for calcium responses $\left(\mathrm{pEC}_{50}=7.0\right)$ does not furnish a $\mathrm{p} K_{\mathrm{B}}$ estimate consistent with the antagonist activity of alvameline and mass action kinetics, i.e., the calcium assay gives a conflicting pattern of transient response and noncompetitive blockade that does not adhere to mass action kinetics. It should be noted that pre-equilibration formats sometimes express the first read (agonism) of the test compound as the basal for subsequent events in the presence of the first ligand; under these circumstances, the initial read for alvameline would form the new baseline for the subsequent challenge to $\mathrm{ACh}$ and the response to the additive. There is no theoretical or practical validation for this procedure since it cannot be known what the level of response to alvameline would be after the 30-minute incubation and challenge with ACh. For completeness, the data for alvameline and ACh for the pre-equilibration protocol were calculated to show how this method of response presentation would affect the curves for alvameline and ACh; this is shown in Supplemental Fig. 2. From this analysis it can be seen that simply applying the initial read to the baseline for the alvameline + ACh effect does not provide data that fit standard mass action partial agonist kinetics.

With simultaneous addition of alvameline and acetylcholine (coaddition format) in the calcium assay, an apparent classic pattern of partial agonism for alvameline is observed (see Fig. 5A). Specifically, the basal responses are elevated and the responses to acetylcholine are slightly blocked by alvameline. However, the resulting direct agonism by alvameline (as indicated by the elevated baseline) and the Schild regression from acetylcholine antagonism by alvameline yield a pattern of partial agonism that is inconsistent with equilibrium mass action kinetics. The effects of inadequate equilibration inherent in the coaddition format can be simulated with kinetic equations given by Motulsky and Mahan (1984); see Materials and Methods. An example of the relative receptor occupancies of a fast onset/offset full agonist (A) coadded with a slower acting partial agonist $\mathrm{B}$ is shown in Fig. 5B. The hemiequilibrium window is the earliest receptor occupancy imposed on the experiment by the calcium assay [the hemiequilibrium condition as described by Paton and Rang (1965)]. It can be seen from Fig. 5B that the response is dominated by the fast acting agonist. Once equilibrium has been obtained (as can be achieved in IP1 assays), the correct relative receptor occupancies for both ligands are observed. In the hemiequilibrium window, the low receptor occupancy by the partial agonist may contribute to an elevated basal response due to the positive intrinsic efficacy of the partial agonist in systems with high receptor reserve. However, the correct receptor occupancy cannot be determined since it takes longer to attain equilibrium receptor occupancy than can be observed in the window available to measure response. The result is that agonism is produced with very little, if any, antagonism (see Fig. 5C). Thus, the antagonism measured in this assay format grossly underestimates antagonist potency, as seen in the dextral displacement of the Schild regression shown in Fig. 5D. In summary, it can be seen that while the IP1 assay reveals alvameline to be a standard partial agonist, the calcium assay gives a conflicting pattern of transient response and noncompetitive blockade that does not adhere to mass action kinetics and yields erroneous potency data regardless of the protocol used (pre-equilibration and coaddition format).

Characterization of Inverse Agonists. Another possible activity present in any antagonist molecule is negative efficacy due to the selective affinity of the antagonist for the inactive state of the receptor. This translates to a depression of any constitutive receptor activity present in the system due to the existence of spontaneously activated receptors; the ligands that produce this effect are labeled inverse agonists (Costa and Herz, 1989; Samama et al., 1993). To evaluate this, responses to ghrelin were obtained in HEK293 cells stably transfected with human ghrelin receptors in the absence and presence of the known ghrelin receptor inverse agonist SPA (Holst et al., 2003). Using IP1, the constitutive receptor activity of the system is demonstrated by the concentration-related depression of basal responses by $\mathrm{SPA}$ (Fig. 6); the $\mathrm{pEC}_{50}$ value for inverse agonism is 7.0. The effects of SPA on ghrelin receptors also were examined with ghrelin-induced increased calcium transient responses in the same HEK293-GHSR1a cells. In contrast to the effects with IP1, no changes in the basal responses to SPA were observed in the calcium assay (Fig. 6), as expected since the calcium assay does not support a sustained constitutively elevated basal response due to active state receptors.

In the IP1 assay, concentration-response curves to ghrelin are shifted to the right with concomitant depression of basal response in a concentration-dependent manner by SPA (see Fig. 7A). In the calcium assay, SPA also produced antagonism of ACh responses but no changes in baseline (consistent with Fig. 6) were observed (see Fig. 7B). This profile is not consistent with predictions of standard mass action inverse agonism (see Fig. 7C). The dextral displacements of the concentration-response curves to ghrelin in the IP1 assay yield a linear Schild regression (slope $=1.0,95 \%$ confidence limit $=0.9-1.1$ ) with $\mathrm{p} K_{\mathrm{B}}=7.47$ and $95 \%$ confidence limit $=$ 7.6-7.34, which agree with published binding data for SPA $\left(K_{\mathrm{B}}=45 \mathrm{nM}\right.$; Holst et al., 2003), see Fig. 7D. In addition, the $\mathrm{p} K_{\mathrm{B}}$ value measured in the IP1 assay is slightly lower than the $\mathrm{EC}_{50}$ value for reversal of basal response (direct inverse agonism) seen in Fig. $6\left(\mathrm{EC}_{50}=0.1 \mu \mathrm{M} ; K_{\mathrm{B}}=33.9 \mathrm{nM}\right)$, in agreement with theoretical predictions (Kenakin, 2014). In summary, while the IP1 assay demonstrates known inverse agonism for SPA, the calcium assay does not show an inverse agonist effect but rather presents a simple competitive antagonist profile for this compound. 
A

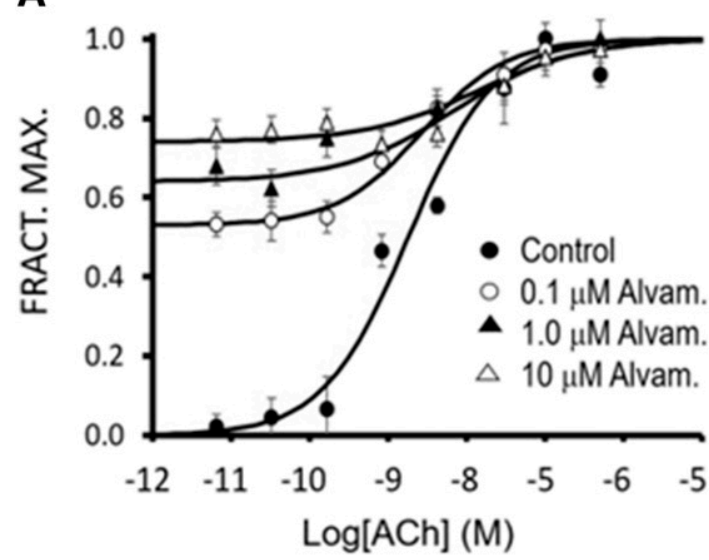

C

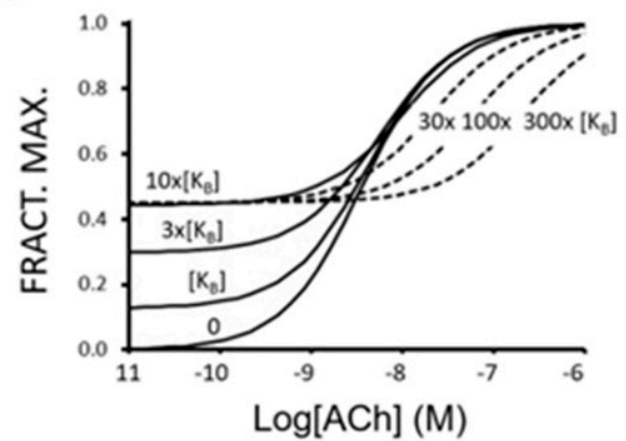

B
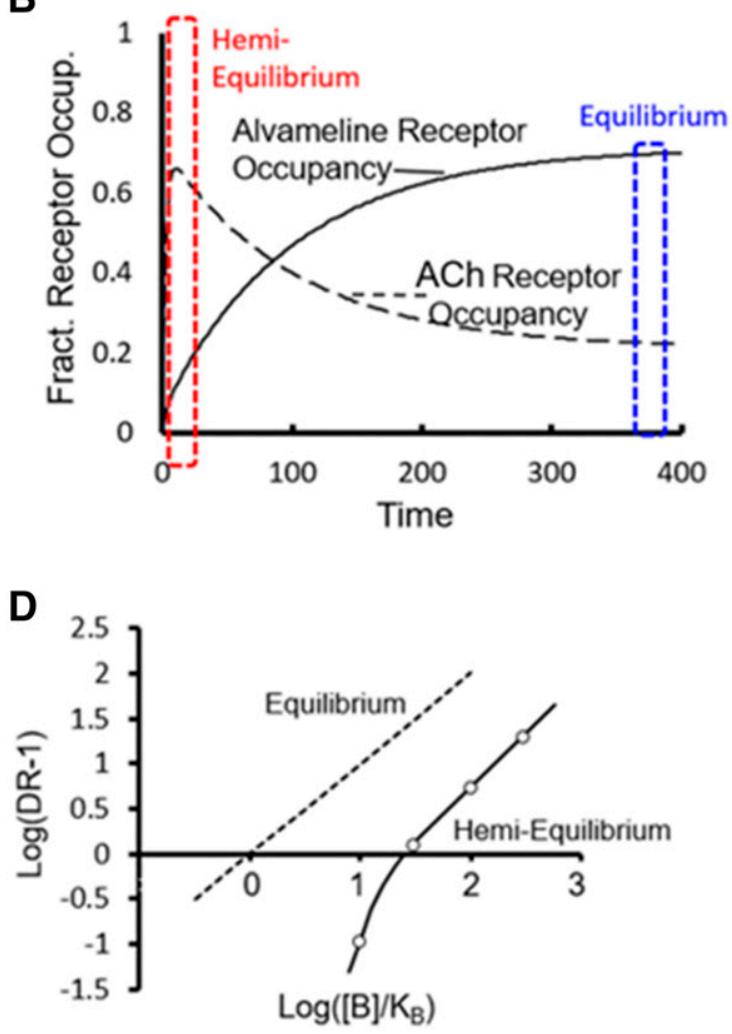

Fig. 5. Coaddition of a fast acting agonist (ACh) and slower acting partial agonist (alvameline) in CHO-M1 cells (alvameline and ACh added simultaneously). (A) Concentration-response curves in the calcium assay (coaddition format) in the absence (filled circles) and presence of increasing concentrations of alvameline (open circles, $0.1 \mu \mathrm{M}$; filled triangles, $1 \mu \mathrm{M}$; open triangles, $10 \mu \mathrm{M}$ ). Data from representative experiments are shown $(n=4)$. Error bars represent S.D. (B) Simulations of full agonist (broken line) and partial agonist (filled line) receptor occupancy. Full agonist: $k_{1}=10^{5} \mathrm{Ms}^{-1}, k_{2}=$ 0.06 second $^{-1}$; partial agonist: $k_{1}=10^{6} \mathrm{Ms}^{-1} ; k_{2}=0.01$ second $^{-1}$. (C) Hemi-equilibrium kinetic responses calculated through receptor occupancies from eq. 4 furnishing $[\mathrm{A}] / K_{\mathrm{A}}$ values through $\rho_{\mathrm{A}} /\left(1-\rho_{\mathrm{A}}\right)$ in the operational model (eq. 1$)$ at time $=3$ seconds. It can be seen that partial agonist concentrations up to $10 \mathrm{X} K_{\mathrm{B}}$ produce no antagonism [solid lines model experimental data shown in (A)]. Only at concentrations $>10 \mathrm{X} K_{\mathrm{B}}$ is antagonism observed; see the simulated concentration-response curves in the dashed lines). (D) Concentrations producing antagonism [dashed lines in (C)] produce a curvilinear Schild regression with an intercept shifted to the right of the correct $K_{\mathrm{B}}$ at equilibrium.

Characterization of PAM Agonists. PAMs potentiate agonist responses through stabilization of the agonist-promoted active receptor state. An added degree of positive activity can be gained with PAM agonists, which in addition to potentiation of endogenous agonist response also can impart a direct positive agonist response to the system through direct positive efficacy in the modulator. An example of such a compound is BQCA (Ma et al., 2009; Mistry et al., 2016), a PAM agonist for the M1 muscarinic receptor. Concentration-response curves to acetylcholine, in the absence and presence of BQCA, illustrate the expected PAM agonist profile of BQCA in CHO cells containing muscarinic M1 receptors as measured with IP1 response (see Fig. 8). The pattern of responses to ACh (all concentrationresponse curves fit simultaneously) with varying concentrations of BQCA was fit to the functional allosteric equation (eq. 11) to yield the predictive activity parameters of $K_{\mathrm{B}}=5 \mu \mathrm{M}$, $\tau_{\mathrm{B}}=0.24 \times \tau_{\mathrm{ACh}}, \alpha=12$, and $\beta=2$. The effects of BQCA in the IP1 assay are consistent with the theoretical predictions of the functional allosteric model (Fig. 8B). It is interesting to note that no agonism is observed for concentrations that produce acetylcholine potentiation (i.e., $1 \mu \mathrm{M}$ ) (see Fig. 8A); however, this is common with PAM agonists. Specifically, since the endogenous agonist increases the affinity of the PAM when bound to the receptor, potentiation of PAM effects is expected to be observed at concentrations lower than those producing direct agonism; this is what is observed for IP1 (see Fig. 8C) (Davoren et al., 2017). This being the case, the fact that potentiation is seen at concentrations lower than those producing direct agonism is consistent with expectations of this allosteric system.

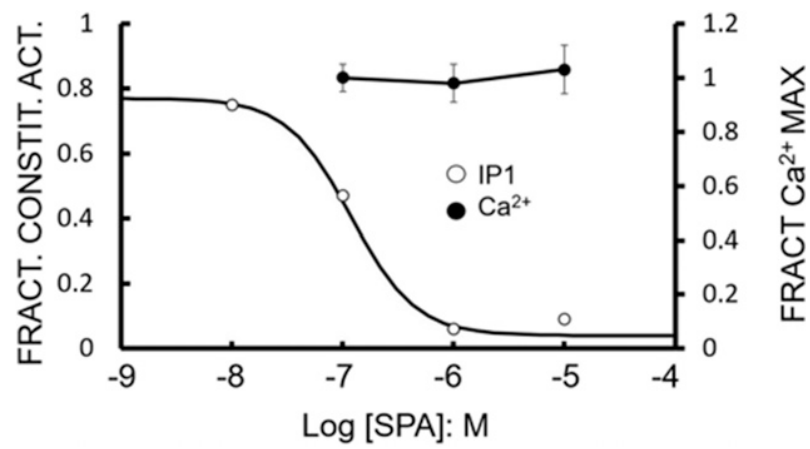

Fig. 6. Effects of inverse agonist SPA on constitutive receptor activity of HEK293-GHSR1a. Dose-response curves were obtained with the IP1 assay (open circles) or calcium assay (filled circles). Data from representative experiments are shown $(n=3)$. Error bars represent S.D. and abscissae molar concentration of SPA (log scale). 
A

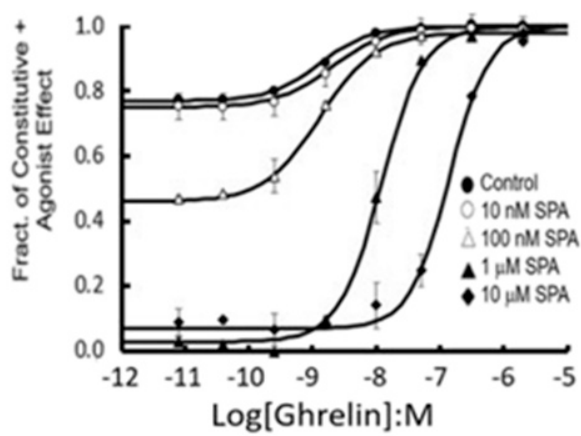

C

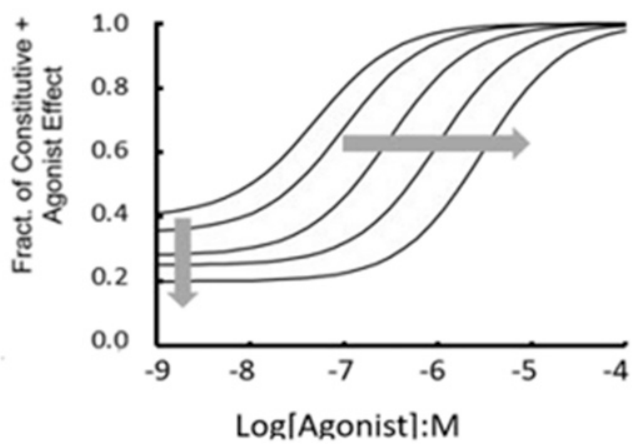

B

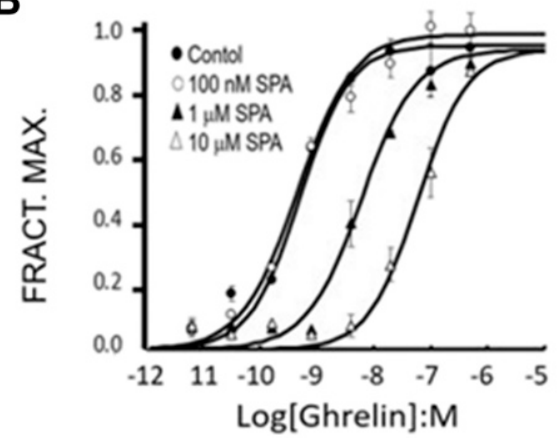

D

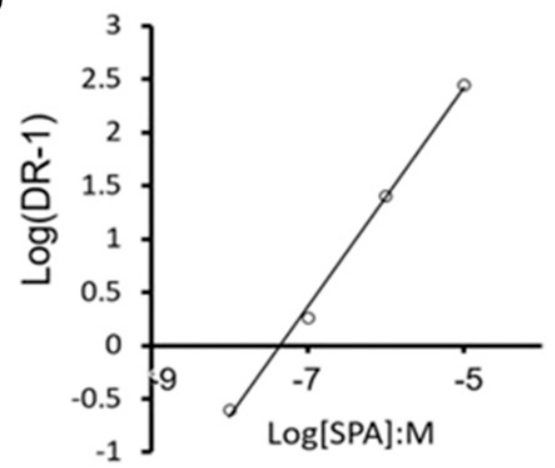

Fig. 7. Effects of the inverse agonist SPA on ghrelin-mediated response of HEK293GSHR1a cells in pre-equilibration format (SPA added 60 minutes before determination of ACh response). (A) IP1 assay: responses obtained in the absence (filled circles) or presence of increasing concentrations of SPA [10 nM (open circles), $100 \mathrm{nM}$ (open triangles), $1 \mu \mathrm{M}$ (filled triangles), and $10 \mu \mathrm{M}$ (filled diamonds)]. (B) Calcium assay: responses obtained in the absence (filled circles) or presence of increasing concentrations of SPA [100 nM (open circles), $1 \mu \mathrm{M}$ (filled triangles), and $10 \mu \mathrm{M}$ (open triangles)]. (C) Theoretically predicted effects of an agonist in the presence of increasing concentration of an inverse agonist in a constitutively active receptor system according to the mass action inverse antagonism equation (Kenakin, 2014). (D) Schild regression for SPA blockade of ghrelin responses in (A). Slope $=1.0,95 \%$ confidence limit $($ c.l. $)=$ $0.9-1.1 ; \mathrm{p} K_{\mathrm{B}}=7.47,95 \%$ c.l. $=7.6-7.34$. Data from representative experiments are shown $(n \geq 3)$. Error bars represent S.D. and abscissae as molar concentrations (logarithmic scale).
In contrast to the patterns of responses seen with BQCA in the IP1 assay, the pre-equilibration format with calcium yields transient responses that do not demonstrate predicted PAM agonist behavior. As seen in Fig. 9A, with 30-minute preincubation BQCA produces some measure of sinistral displacement of concentration-response curves to ACh. However, the estimated value of $\alpha$ is considerably less than that observed with the IP1 assay $\left(\alpha_{\text {Calcium }}=4.5 ; \alpha_{\mathrm{IP} 1}=12\right)$. More importantly, the positive agonism of BQCA is not observed and the maximal responses to $\mathrm{ACh}$ are distorted, most likely due to the hemi-equilibrium nature of the calcium transient assay and also possible desensitization of response (Kenakin et al., 2006).

The characterization of BQCA by the pattern of calcium responses is one of increased affinity and decreased efficacy; however, importantly, this pattern of effect seen with BQCA is not amenable to fit by the functional allosteric model. Specifically, any value for $\alpha$ that fits the sinistral displacement of any one of the concentration-response curves precludes a fractional value of $\beta$ to concomitantly accommodate the depressed maximal response. In fact, the test for internal consistency of the data with the mathematical model fails in that no combination of $\alpha$ and $\beta$ values can fit the complete pattern of responses (see Fig. 9, B-D). In general, a standard PAM agonist profile is not observed for BQCA, nor is the allosteric nature of BQCA seen with the calcium assay employed in the pre-equilibration format. In contrast, a pattern of effect more consistent with PAM agonism is observed in the calcium assay with coaddition of $\mathrm{ACh}$ and BQCA. As seen in Fig. 10A, some elevated baselines due to direct agonism and some sinistral displacements of ACh concentration-response curves are observed. However, attempts to fit this pattern to the functional allosteric model again failed since no combination of $\alpha, \beta$, and $\tau_{\mathrm{B}}$ enabled fitting of the complete set of concentration-response curves to the allosteric model (see Fig. 10, B-D).

In summary, IP1 and calcium assays display different patterns. On the one hand, the IP1 assay defines the BQCA as a PAM agonist for acetylcholine agonism and gives values $\left(\alpha, \beta\right.$, and $\left.\tau_{\mathrm{B}}\right)$ that can be used to predict the effects of BCQA on $\mathrm{ACh}$ responses in any functional assay varying in sensitivity and receptor expression. On the other hand, the calcium assay with both pre-equilibration and coaddition formats fails in the accurate characterization of the BQCA as a PAM agonist.

Characterization of $\boldsymbol{\beta}$-PAMs. PAMs potentiate agonist responses through either an increase in the affinity of the receptor for the agonist (cooperativity term $\alpha$ ) and/or an increase in the efficacy of the agonist (cooperativity term $\beta$ ). Increased affinity for the endogenous agonist will potentiate responses only when there is appreciable endogenous response remaining to activate the system. In cases where the system is depleted or otherwise attenuated, it may be that an increased affinity for the endogenous signal would not be sufficient to restore a physiologically normal response. In these cases, it may be that the actual efficacy of the endogenous agonist may need to be increased; this is accommodated by cooperativity factor $\beta$ in the functional allosteric model. Therefore, in therapeutic programs for PAMs that are designed to revitalize failing systems (i.e., Alzheimer's disease) it is important to differentiate potentiating effects due to affinity $(\alpha)$ versus efficacy $(\beta)$ since the latter may be the only molecules of value.

A prerequisite to identification of a positive $\beta$-PAM effect is the ability to increase the maximal response in the functional assay (Stahl et al., 2011) as in the case of alvameline, a partial agonist. Increased maximal responses to the PAM agonist BQCA are observed with the partial agonist alvameline with the IP1 assay (Fig. 11A), thus characterizing BQCA as a 
A
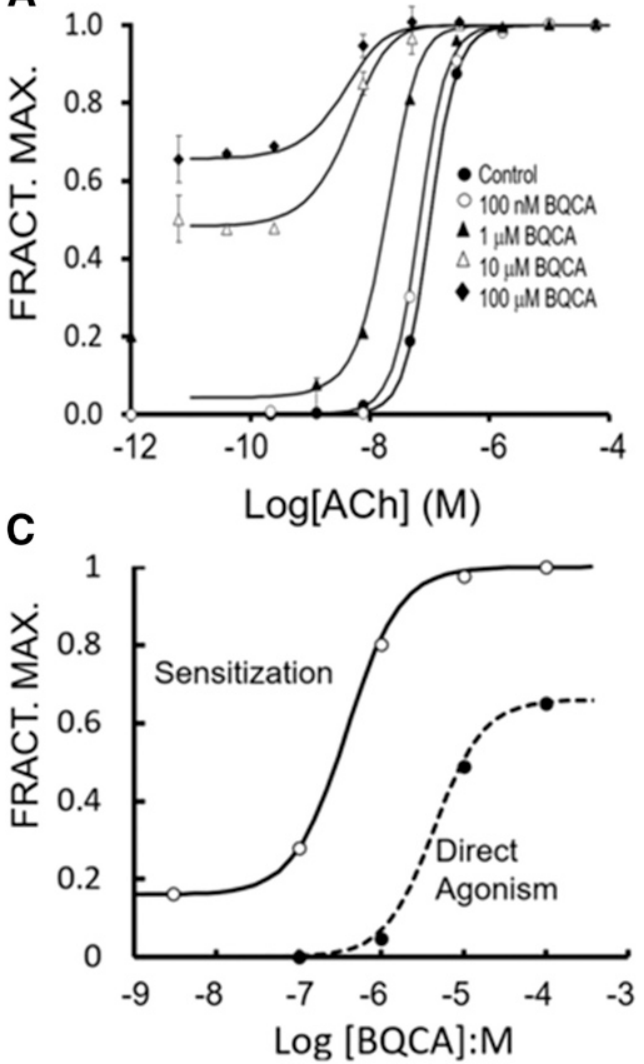

B

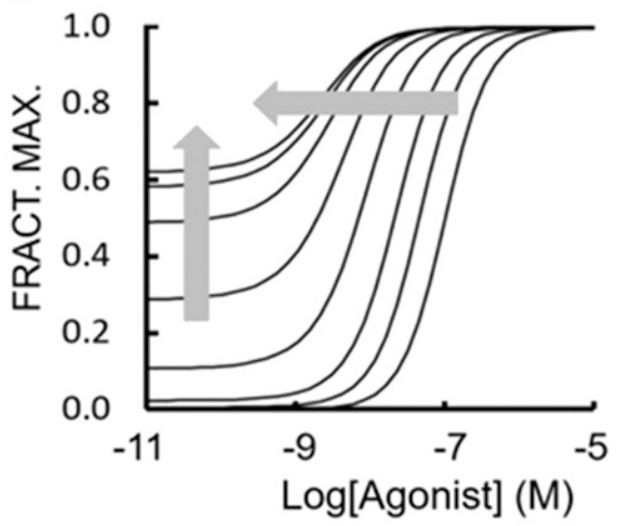

Fig. 8. Effects of a PAM agonist BQCA on ACh-mediated responses of CHO-M1 cells in pre-equilibration format (BQCA added 60 minutes before determination of $\mathrm{ACh}$ response) with the IP1 assay. (A) IP1 assay: dose-response curves of $\mathrm{ACh}$ in the absence (filled circles) or presence of increasing concentrations of BQCA: $100 \mathrm{nM}$ (open circles), $1 \mu \mathrm{M}$ (filled triangles), $10 \mu \mathrm{M}$ (open triangles), and $100 \mu \mathrm{M}$ (filled diamonds). Data from representative experiments are shown $(n \geq 3)$. Error bars represent S.D. and abscissae as molar concentrations (logarithmic scale). The complete set of curves is fit to eq. 11 utilizing parameters $K_{\mathrm{A}}=5 \mu \mathrm{M}, \tau_{\mathrm{A}}=50$, $K_{\mathrm{B}}=5 \mu \mathrm{M}, \tau_{\mathrm{B}}=0.24 \tau_{\mathrm{ACh}}, \alpha=12$, and $\beta=2$. (B) Theoretically predicted effects of an agonist in the presence of increasing concentrations of PAM agonist with positive $\alpha$ and $\beta$ activity according to eq. 11. (C) Data from (A) are recalculated to show the dependence of sensitization of acetylcholine responses and direct agonism to BQCA as a function of BQCA concentrations. The fact that acetylcholine increases the affinity of BQCA for the receptor is reflected in the sinistral displacement of the potentiation curve compared with the agonist curve.
$\beta$-PAM. Fitting the concentration-response curves to the functional allosteric model (eq. 11) reveals that allosteric cooperativity constants of $\alpha=1.2$ and $\beta=80$ with positive efficacy $\tau_{\mathrm{B}}=2.8 \tau_{\mathrm{A}}$ and $K_{\mathrm{B}}=70 \mu \mathrm{M}$ fit the complete set of experimentally derived concentration-response curves. This is in keeping with the predictions of the functional allosteric model (see Fig. 11B), and these data define BQCA as a positive $\beta$-PAM agonist for alvameline agonism. In contrast, very little sensitization and no change in the maximal response to alvameline is observed with BQCA in the calcium assay (Fig. 12). This pattern of responses is inconsistent with that predicted by the functional allosteric model. A somewhat closer pattern to a $\beta$-PAM agonist profile was observed with the coaddition format (Fig. 13A). However, as with the BQCA data utilizing acetylcholine, attempts at fitting the functional allosteric model to the complete set of curves failed (Fig. 13, B-D); thereby, precluding classification of BQCA as a $\beta$-PAM agonist for alvameline with calcium. In summary, while the IP1 assay accurately defines BQCA as a $\beta$-PAM agonist for alvameline agonism and gives consistent values $\left(\alpha, \beta\right.$, and $\left.\tau_{\mathrm{B}}\right)$, the calcium assay fails in this characterization regardless of the protocol used (pre-equilibration and coaddition formats).

\section{Discussion}

By using the appropriate experimental models and assays, pharmacologists aim to describe how a given drug may produce varying effects in different organs under different physiologic conditions through a single mechanism of action. These models thus convert descriptive data (issued from experiments) into predictive data (which can predict the same drug's behavior in all tissues, including the therapeutic setting). A critical part of this process is an accurate assessment of the fit of the experimental patterns of data to the models. In addition, the best models have rules, which can be used in the form of mathematical relationships and equations that can then be used to predict effects under a variety of circumstances. As expressed by Stephen Hawking (Hawking, 1998), "What is it that breathes fires in the equations that makes a Universe for them to describe?" An important corollary to this idea is that mathematical models have internal checks, which link experimental observations to patterns predicted by the model, and these must be applied -i.e., if the observed data do not adhere to these internal checks then the model is a poor representation of the system. For this assessment to be effective, good experimental practice must be exercised to accurately reflect the mass action effects of a drug as it interacts with its biologic target (i.e., preincubation of test compounds), and the assay needs to accurately reflect the mass action kinetics of the drugs involved.

In cells, activation of a Gq-protein-coupled receptor results in increased metabolism of inositol phosphate to cause calcium release and other physiologic effects. These present studies confirm that, with the exception of the inverse agonism and the PAM agonism in the pre-equilibration format, both IP1 and calcium assays accurately detect compound effects on receptor activity in the screening mode. However, when these two assay formats are compared for lead optimization of compounds, differences are observed and these differences emanate from the relative kinetics of the agonistligand interaction with the receptor; if the assay does not reflect the real-time kinetics of physiologic response 
A
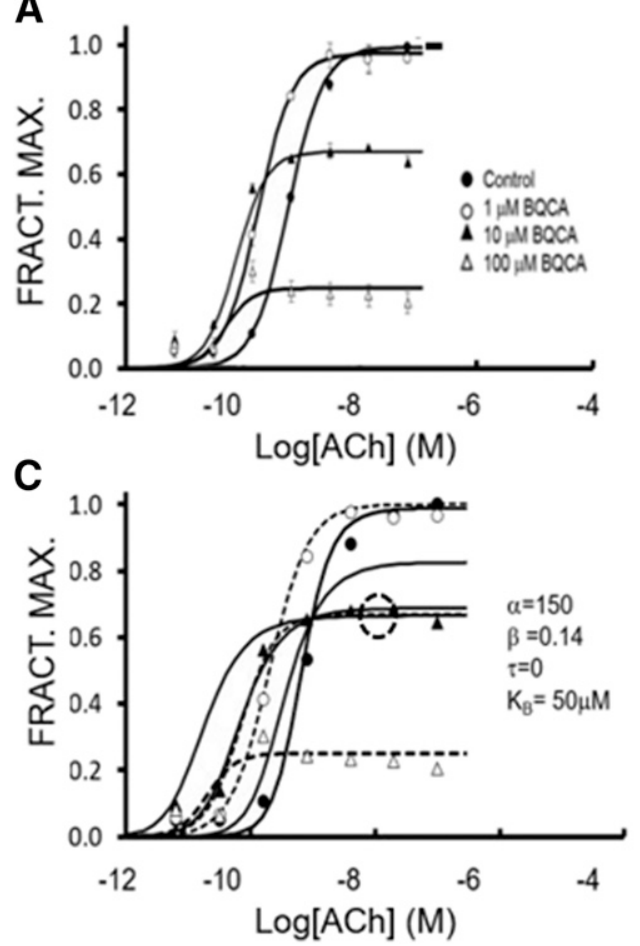

B
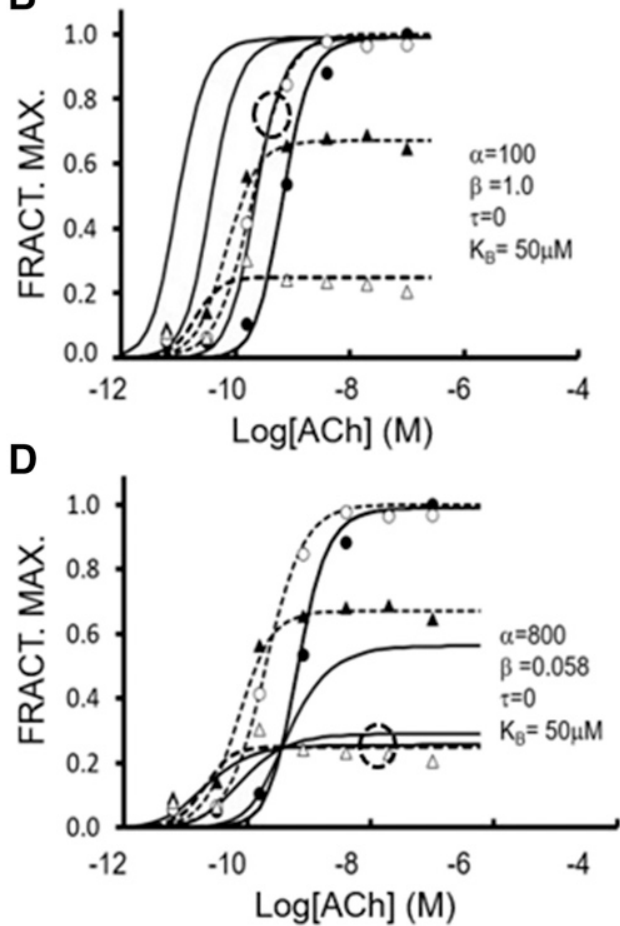

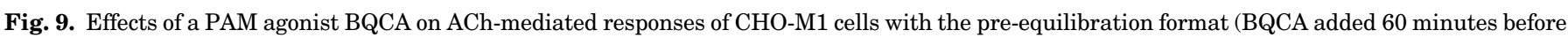

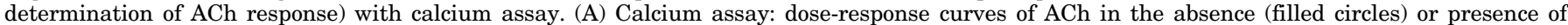

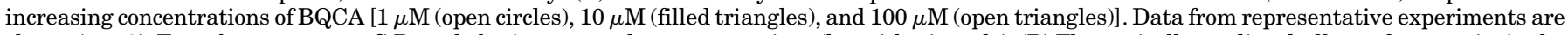

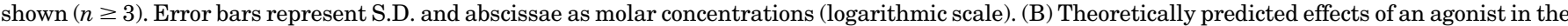

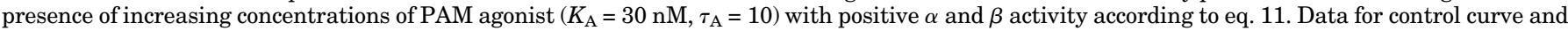

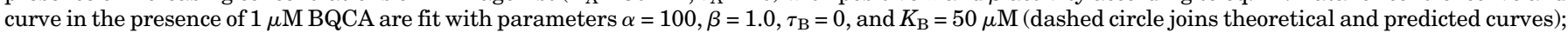

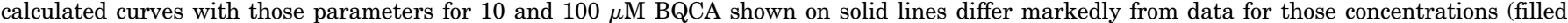

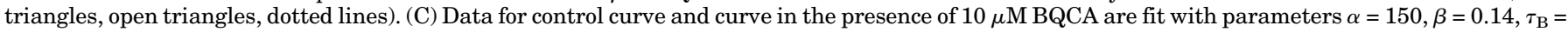

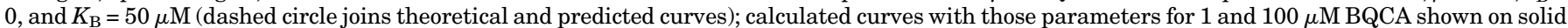

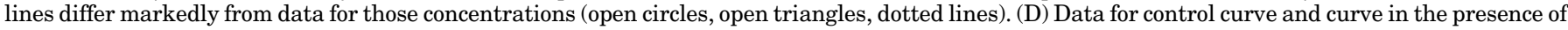

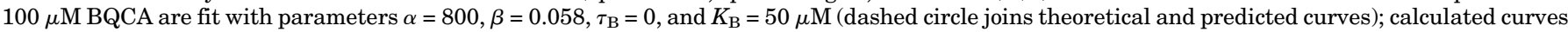

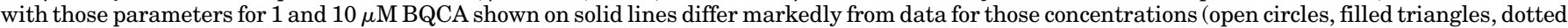
lines).

production, then dissimulations between true mass action drug interactions and observed functional responses can result. For equilibrium assays such as IP1, this error can be eliminated by simply taking measurements after the appropriate equilibration time; however, the transient nature of the response of the calcium assay precludes this.

While both assay formats are suitable for the characterization of antagonists (Fig. 3), differences are observed when the test molecule has positive or negative efficacy on the receptor activity. The Black-Leff operational model applied to the direct partial agonism of alvameline (Fig. 2) yields very different affinity and efficacy values for alvameline in the IP1 and calcium assays, while they should be independent parameters characterizing alvameline agonism in all systems. At this point, the application of internal checks becomes important to assess which set of values are correct. The IP1 assay provides antagonism of ACh responses by alvameline $\left(\mathrm{p} K_{\mathrm{B}}=5.5\right.$; Fig. 4D) identical to the alvameline agonism $\left(\mathrm{pEC}_{50}=5.5\right.$; Fig. $\left.2 \mathrm{~A}\right)$, which is internally consistent with the model, thereby fulfilling the requirement of internal check agreement; the same is not true for the calcium data. Although antagonism is observed with alvameline, the calcium assay produces an aberrant Schild regression that is not consistent with competitive antagonism (Fig. 4D), which is inconsistent with the $\mathrm{p} K_{\mathrm{B}}$ value found for IP1 (5.5) and the $\mathrm{pEC}_{50}$ value in the calcium assay $\left(\mathrm{pEC}_{50}=7.0\right)(\mathrm{Fig} .2 \mathrm{~B})$.

Coaddition of partial and full agonists in the calcium assay produced a pattern of curves closer to what would be expected for mass action partial agonism. However, the observed agonism did not agree with the observed antagonism. Specifically, while the $\mathrm{pEC}_{50}$ value for direct agonism by alvameline was on the order of 0.1-1 $\mu \mathrm{M}$, these agonist responses were not linked to any substantial degree of receptor antagonism. This pattern is predicted by simulations of coaddition of a fast-acting full agonist and a slower acting partial agonist, where the response is measured at times less than those required for equilibrium (Fig. 5, B and C). The coaddition of partial and full agonists in the calcium assay predicts the appearance of agonism with a severe underestimation of antagonism (Fig. 5D).

Another type of ligand that cannot adequately be identified or profiled in hemi-equilibrium assays is the inverse agonist. Since inverse agonism has been associated with clinical tolerance to antagonism (Wilder-Smith et al., 1990; Deakin and Williams, 1992), it is critical to differentiate them from antagonists in discovery programs. While the inability of the calcium assay to produce sustained, elevated basal responses precludes detection of inverse agonism it is still worth applying internal checks to the data obtained with the IP1 

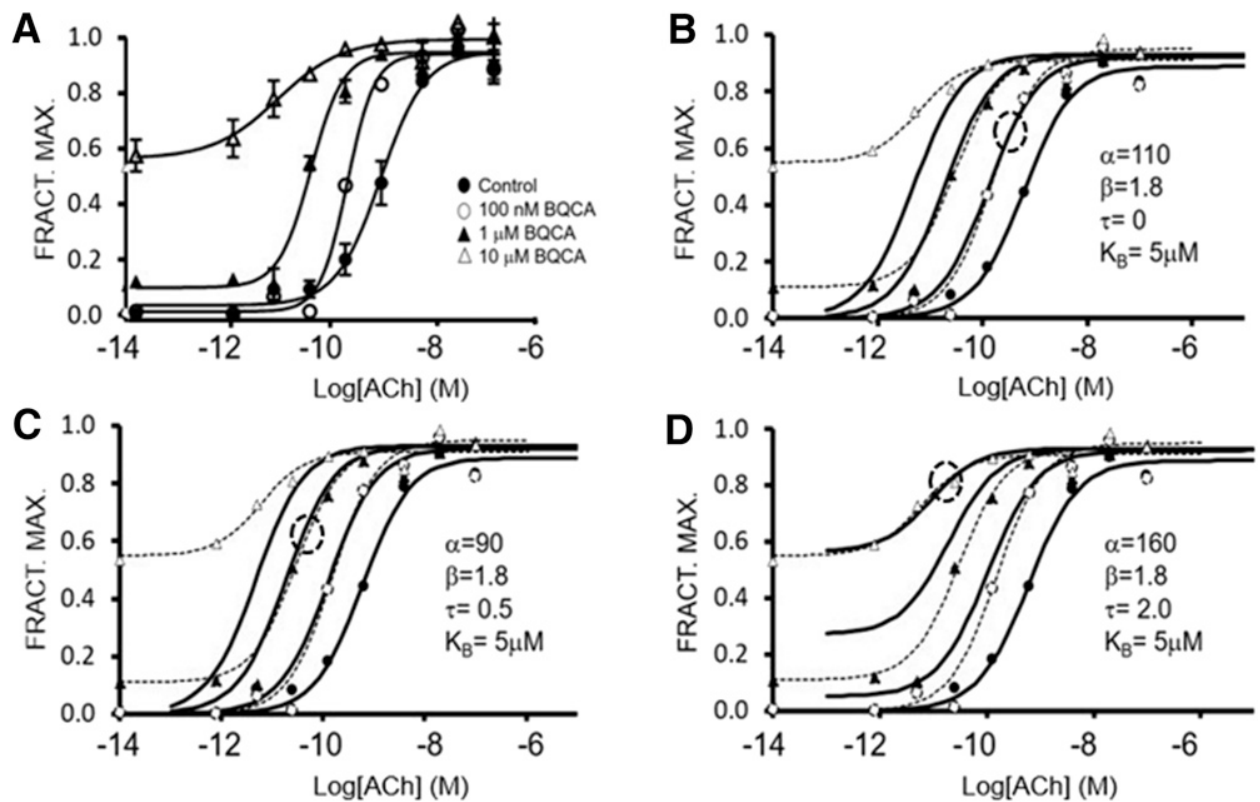

Fig. 10. Effects of a PAM agonist BQCA on ACh-mediated responses of CHO-M1 cells with the coaddition format (BQCA and ACh added together) with calcium assay. (A) Calcium assay: dose-response curves of ACh in the absence (filled circles) or presence of increasing concentrations of BQCA [100 nM (open circles), $1 \mu \mathrm{M}$ (filled triangles), and $10 \mu \mathrm{M}$ (open triangles)]. Data from representative experiments are shown $(n \geq 3)$. Error bars represent S.D. and abscissae as molar concentrations (logarithmic scale). (B) Theoretically predicted effects of an agonist $\left(K_{\mathrm{A}}=30 \mathrm{nM}, \tau_{\mathrm{A}}=10\right)$ in the presence of increasing concentrations of PAM agonist with positive $\alpha$ and $\beta$ activity according to eq. 11. Data for control curve and curve in the presence of $100 \mathrm{nM}$ BQCA are fit with parameters $\alpha=100, \beta=1.0, \tau_{\mathrm{B}}=0$, and $K_{\mathrm{B}}=5 \mu \mathrm{M}$ (dashed circle joins theoretical and predicted curves); calculated curves with those parameters for 1 and $10 \mu \mathrm{M}$ BQCA shown on solid lines differ markedly from data for those concentrations (filled triangles, open triangles, dotted lines). (C) Data for control curve and curve in the presence of $1 \mu \mathrm{M}$ BQCA are fit with parameters $\alpha=110, \beta=1.8, \tau_{\mathrm{B}}=0$, and $K_{\mathrm{B}}=50 \mu \mathrm{M}$ (dashed circle joins theoretical and predicted curves); calculated curves with those parameters for $100 \mathrm{nM}$ and $10 \mu \mathrm{M}$ BQCA shown on solid lines differ markedly from data for those concentrations (open circles, open triangles, dotted lines). (D) Data for control curve and curve in the presence of $10 \mu \mathrm{M}$ BQCA are fit with parameters $\alpha=100, \beta=1.0, \tau_{\mathrm{B}}=1.55$, and $K_{\mathrm{B}}=50 \mu \mathrm{M}$ (dashed circle joins theoretical and predicted curves); calculated curves with those parameters for $100 \mathrm{nM}$ and $1 \mu \mathrm{M}$ BQCA shown on solid lines differ markedly from data for those concentrations (open circles, filled triangles, dotted lines).

assay. Specifically, the internal check for inverse agonism dictates that the $\mathrm{EC}_{50}$ value for reversal of constitutive activity should always be arithmetically larger than the $K_{\mathrm{B}}$ value for binding (see Results), and this was indeed the case with the IP1 assay (see Fig. 6; Fig. 7D).

Finally, study of allosteric modulation mediated by Gq proteins was investigated with the IP1 and calcium assays using BQCA, a PAM agonist for the muscarinic M1 receptor.
The standard profile of these types of ligands is the potentiation of an agonist response with concomitant elevated basal response due to the direct agonism. This was observed for BQCA in the IP1 assay (Fig. 8), allowing the profile to be compared with the functional allosteric model (Ehlert, 2005; Kenakin, 2005; Price et al., 2005). This, in turn, furnished universal allosteric parameters for effects on affinity $(\alpha)$, efficacy $(\beta)$, direct efficacy $\left(\tau_{\mathrm{B}}\right)$, and binding $\left(K_{\mathrm{B}}\right)$ that fit the
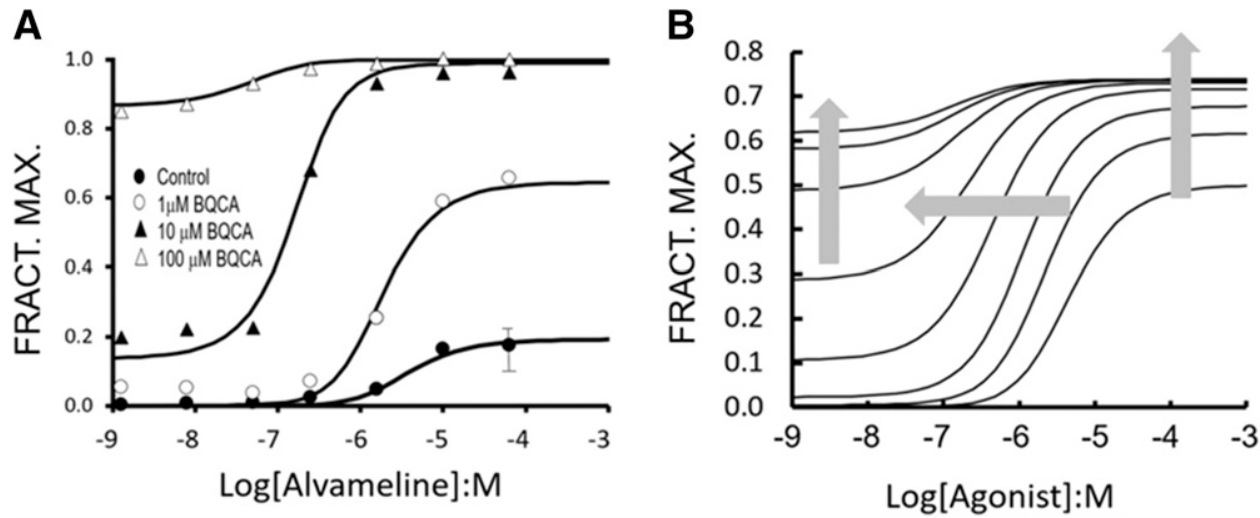

Fig. 11. Effects of BQCA on alvameline-mediated responses on CHO-M1 cells in pre-equilibration format (BQCA added 60 minutes before determination of alvameline response) with the IP1 assay. (A) Alvameline dose-response curves obtained with the IP1 assay in the absence (filled circles) or presence of increasing concentrations of BQCA [1 $\mu \mathrm{M}$ (open circles), $10 \mu \mathrm{M}$ (filled triangles), and $100 \mu \mathrm{M}$ (open triangles)]. Data fit with eq. 11 using parameters $\alpha=1.2, \beta=80, \tau_{\mathrm{B}}=2.8 \tau_{\mathrm{A}}$, and $K_{\mathrm{B}}=70 \mu \mathrm{M}$. (B) Theoretically predicted effects of a PAM agonist with positive $\beta$ effects on a partial agonist, where the window to detect maximal response exceeds the maximal response to the partial agonist according to eq. 11. Data from representative experiments are shown $(n \geq 3)$. Error bars represent S.D. and abscissae values as molar (log scale). 


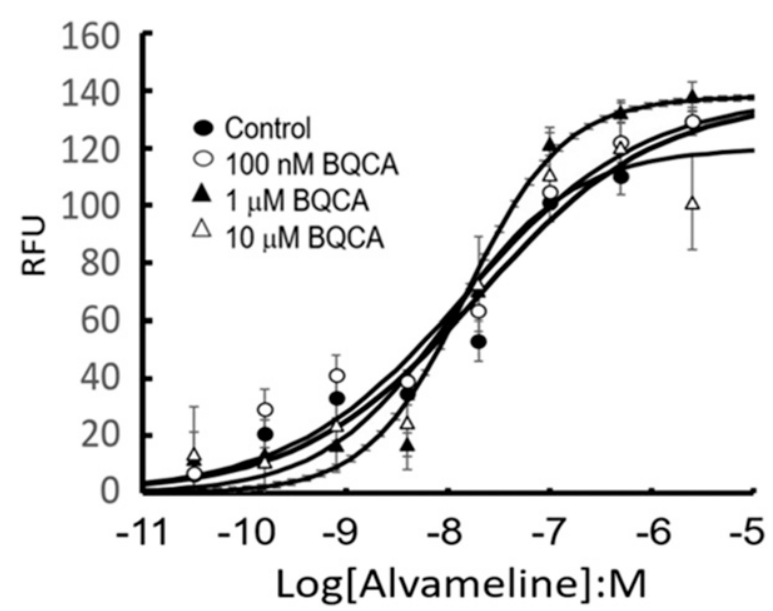

Fig. 12. Effects of BQCA on alvameline-mediated responses on CHO-M1 cells in pre-equilibration format (BQCA added 60 minutes before determination of alvameline response) with the calcium assay. Alvameline dose-response curves obtained with the calcium assay in the absence (filled circles) or presence of increasing concentrations of BQCA [100 nM (open circles), $1 \mu \mathrm{M}$ (filled triangles), and $10 \mu \mathrm{M}$ (open triangles)]. Data from representative experiments are shown $(n \geq 3)$. Error bars represent S.D. and abscissae values as molar (log scale).

entire array of ACh concentration-response curves. The inability of the calcium assay to demonstrate sustained responses precludes observation of the PAM agonist profile of BQCA with the pre-equilibration format (Fig. 9A). While the coaddition format provided curves that at least qualitatively demonstrated elevated direct agonist activity and sensitization of ACh response (Fig. 10A), attempts to fit the resulting pattern of curves to the functional allosteric model failed with both pre-equilibration (Fig. 9, B-D) and coaddition formats (Fig. 10, B-D). The calcium assay would then lead to dissimulation in the classification of BQCA as an allosteric ligand.

A further obfuscation of allosteric effect was observed for BQCA in the failure to detect the $\beta$ effect with alvameline. Positive $\beta$-PAM activity can be an important aspect of an allosteric PAM program since this activity is relevant to the rejuvenation of a failing physiologic system. For example, the D112 $2^{3.32}$ mutant of the muscarinic M4 receptor renders this protein insensitive to ACh but the $\beta$-PAM LY2033298 completely restores activity to ACh (Leach et al., 2011). The pattern of curves obtained in the IP1 assay indicated $\beta$-mediated PAM activity that adhered to the functional allosteric model (Fig. 11). In contrast, the unreliable agonist maximal responses produced in a hemi-equilibrium calcium assay did not reveal the $\beta$ effect (nor indeed any substantial potentiating effect) of BQCA with alvameline (Fig. 12). Although an apparently more favorable profile was observed with the coaddition format, attempts to fit the complete set of curves to the functional model also failed (Fig. 13).

This study uses different classes of G-protein-coupled receptor ligands (antagonists, partial agonists, inverse agonists, and $\alpha / \beta$-PAMs) to demonstrate that functional assays can drive what conclusions are drawn about the mechanism of action of ligands and also their subsequent disposition in lead
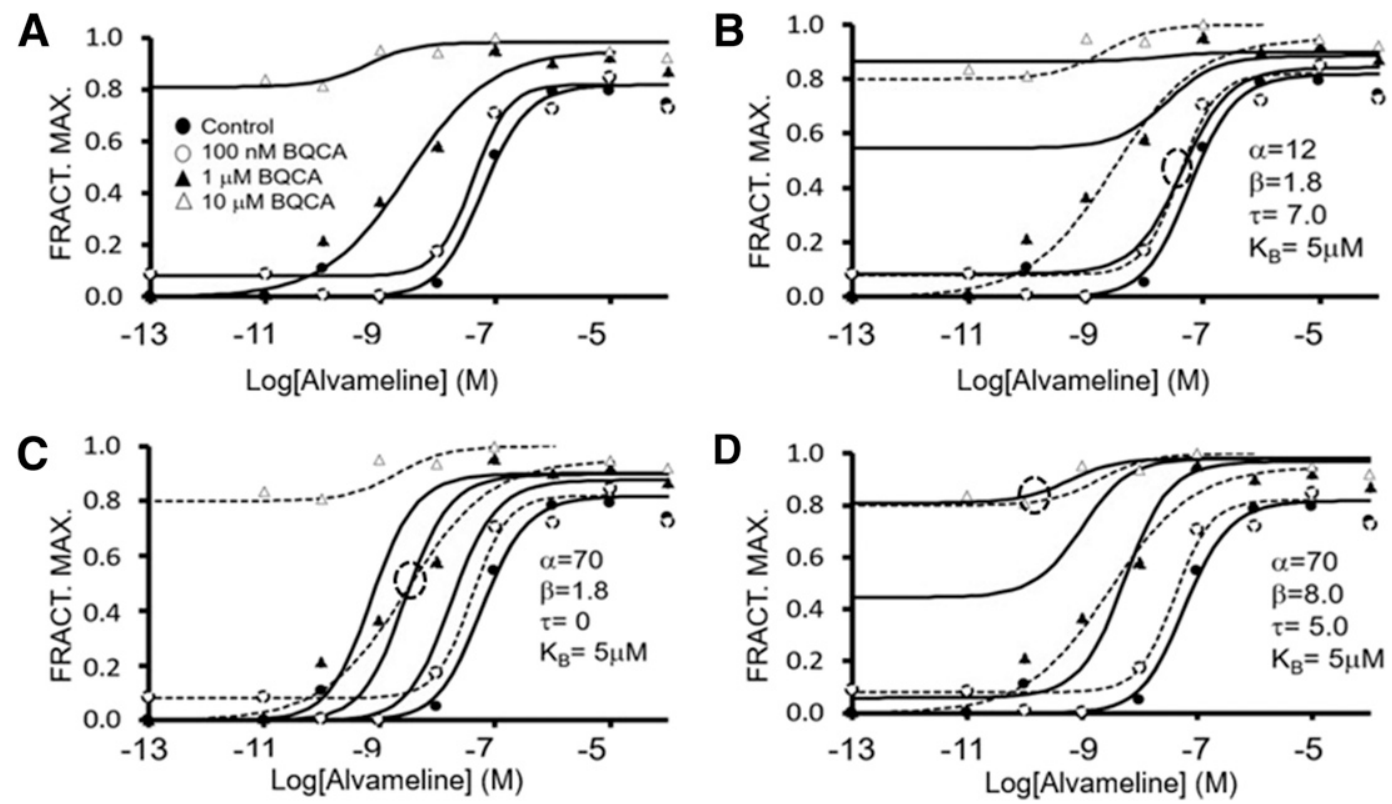

Fig. 13. Effects of a PAM agonist BQCA on alvameline-mediated responses of CHO-M1 cells with the coaddition format (BQCA and Alvameline added together) and the calcium assay. (A) Calcium assay: dose-response curves of alvameline in the absence (filled circles) or presence of increasing concentrations of BQCA [100 nM (open circles), $1 \mu \mathrm{M}$ (filled triangles), and $10 \mu \mathrm{M}$ (open triangles)]. Data from representative experiments are shown $(n \geq 3)$. Error bars represent S.D. and abscissae values as molar (log scale). (B) Theoretically predicted effects of an agonist $\left(K_{\mathrm{A}}=225 \mathrm{nM}, \tau_{\mathrm{A}}=3.5\right)$ in the presence of increasing concentrations of PAM agonist with positive $\alpha$ and $\beta$ activity according to eq. 11. Data for control curve and curve in the presence of $100 \mathrm{nM}$ BQCA are fit with parameters $\alpha=12, \beta=1.8, \tau_{\mathrm{B}}=7$, and $K_{\mathrm{B}}=5 \mu \mathrm{M}$ (dashed circle joins theoretical and predicted curves); calculated curves with those parameters for 1 and $10 \mu \mathrm{M}$ BQCA shown on solid lines differ markedly from data for those concentrations (filled triangles, open triangles, dotted lines). (C) Data for control curve and curve in the presence of $1 \mu \mathrm{M}$ BQCA are fit with parameters $\alpha=70, \beta=1.8, \tau_{\mathrm{B}}=0$, and $K_{\mathrm{B}}=5 \mu \mathrm{M}$ (dashed circle joins theoretical and predicted curves); calculated curves with those parameters for $100 \mathrm{nM}$ and $10 \mu \mathrm{M}$ BQCA shown on solid lines differ markedly from data for those concentrations (filled circles, open triangles, dotted lines). (D) Data for control curve and curve in the presence of $10 \mu \mathrm{M}$ BQCA are fit with parameters $\alpha=70, \beta=8.0, \tau_{\mathrm{B}}=5.0$, and $K_{\mathrm{B}}=5 \mu \mathrm{M}$ (dashed circle joins theoretical and predicted curves); calculated curves with those parameters for $100 \mathrm{nM}$ and $1 \mu \mathrm{M}$ BQCA shown on the solid lines differ markedly from data for those concentrations (open circles, filled triangles, dotted lines). 
optimization programs. In cases where a sustained response is required, it is obvious that the calcium assay in the preequilibration format should not be used to determine drug activity parameters. Specifically, it has been shown that a hemi-equilibrium assay such as calcium incorrectly identifies alvameline as a noncompetitive antagonist of muscarinic receptors (as opposed to a partial agonist), does not identify the inverse agonist activity of SPA, and does not identify BQCA as a PAM with direct positive cooperative potentiation of the effect of muscarinic agonist activity. Even when utilizing coaddition of the ligand format-where apparently correct patterns of concentration-response curves are obtained experimentallyquantitative analyses of the data and application of internal checks indicate that standard partial agonist activity for alvameline and true PAM agonist activity for BQCA cannot be verified. In contrast, all these profiles are accurately demonstrated with an equilibrium assay such as IP1, and were confirmed by internal checks of parameters determined from the models.

The most prevalent reason for failure of new drug candidates is lack of efficacy (Arrowsmith, 2011). Clearly, a large part of the reason for this is our current inability to understand disease and what is required to modify physiology to reverse these processes. However, it may also be true that inability to properly characterize the efficacy of the molecules we advance in clinical trials plays a part in these failures. The corollary to this idea is that any pharmacological procedure(s) that can correctly characterize pharmacological profiles for new compounds targeting G-protein-coupled receptors is an obviously important endeavor, which can be addressed through the proper use of equilibrium assays. The definition of the true efficacy of test molecules can only be beneficial in the discovery process, which hopefully can reduce the current high rate of candidate failures.

\section{Authorship Contributions}

Participated in research design: Bdioui, Verdi, Pierre, Trinquet, Roux, Kenakin.

Conducted experiments: Bdioui, Verdi, Roux.

Contributed new reagents or analytic tools: Kenakin.

Performed data analysis: Bdioui, Verdi, Trinquet, Roux, Kenakin. Wrote or contributed to the writing of the manuscript: Bdioui, Trinquet, Roux, Kenakin.

\section{References}

Arrowsmith J (2011) Trial watch: phase II failures: 2008-2010. Nat Rev Drug Discov 10:328-329.

Arunlakshana O and Schild HO (1959) Some quantitative uses of drug antagonists. Br J Pharmacol Chemother 14:48-58.

Berridge MJ, Bootman MD, and Roderick HL (2003) Calcium signalling: dynamics, homeostasis and remodelling. Nat Rev Mol Cell Biol 4:517-529.

Black JW and Leff P (1983) Operational models of pharmacological agonism. Proc $R$ Soc Lond B Biol Sci 220:141-162.

Black JW, Leff P, Shankley NP, and Wood J (1985) An operational model of pharmacological agonism: the effect of $\mathrm{E} /[\mathrm{A}]$ curve shape on agonist dissociation constant estimation. Br J Pharmacol 84:561-571.

Chambers C, Smith F, Williams C, Marcos S, Liu ZH, Hayter P, Ciaramella G, Keighley W, Gribbon P, and Sewing A (2003) Measuring intracellular calcium fluxes in high throughput mode. Comb Chem High Throughput Screen 6:355-362. Charlton SJ and Vauquelin G (2010) Elusive equilibrium: the challenge of interpreting receptor pharmacology using calcium assays. Br J Pharmacol 161:1250-1265.

Costa T and Herz A (1989) Antagonists with negative intrinsic activity at delta opioid receptors coupled to GTP-binding proteins. Proc Natl Acad Sci USA 86:7321-7325.

Davoren JE, Garnsey M, Pettersen B, Brodney MA, Edgerton JR, Fortin JP, Grimwood S, Harris AR, Jenkinson S, Kenakin T, et al. (2017) Design and synthesis of $\gamma$ - and $\delta$-lactam $\mathrm{M}_{1}$ positive allosteric modulators (PAMs): convulsion and cholinergic toxicity of an $\mathrm{M}_{1}$-selective PAM with weak agonist activity. J Med Chem 60 : $6649-6663$

Deakin M and Williams JG (1992) Histamine $\mathrm{H}_{2}$-receptor antagonists in peptic ulcer disease. Efficacy in healing peptic ulcers. Drugs 44:709-719.

Ehlert FJ (1988) Estimation of the affinities of allosteric ligands using radioligand binding and pharmacological null methods. Mol Pharmacol 33:187-194.

Ehlert FJ (2005) Analysis of allosterism in functional assays. J Pharmacol Exp Ther 315:740-754.

Hawking S (1998) A Brief History of Time, Bantam Books, New York.

Holst B, Cygankiewicz A, Jensen TH, Ankersen M, and Schwartz TW (2003) High constitutive signaling of the ghrelin receptor-identification of a potent inverse agonist. Mol Endocrinol 17:2201-2210.

Kenakin T (2005) New concepts in drug discovery: collateral efficacy and permissive antagonism. Nat Rev Drug Discov 4:919-927.

Kenakin T, Jenkinson S, and Watson C (2006) Determining the potency and molecular mechanism of action of insurmountable antagonists. J Pharmacol Exp Ther 319:710-723

Kenakin TP (1980) Effects of equilibration time on the attainment of equilibrium between antagonists and drug receptors. Eur J Pharmacol 66:295-306.

Kenakin TP (2014) A Pharmacology Primer: Techniques for More Effective and Strategic Drug Discovery, 4th ed, Academic Press/Elsevier, Amsterdam.

Kenakin TP and Black JW (1978) The pharmacological classification of practolol and chloropractolol. Mol Pharmacol 14:607-623.

Kenakin TP and Johnson SF (1985) The importance of the $\alpha$-adrenoceptor agonist activity of dobutamine to inotropic selectivity in the anaesthetized cat. Eur $J$ Pharmacol 111:347-354

Klein Herenbrink C, Sykes DA, Donthamsetti P, Canals M, Coudrat T, Shonberg J, Scammells PJ, Capuano B, Sexton PM, Charlton SJ, et al. (2016) The role of kinetic context in apparent biased agonism at GPCRs. Nat Commun 7:10842.

Leach K, Davey AE, Felder CC, Sexton PM, and Christopoulos A (2011) The role of transmembrane domain 3 in the actions of orthosteric, allosteric, and atypical agonists of the $\mathrm{M}_{4}$ muscarinic acetylcholine receptor. Mol Pharmacol 79:855-865.

Ma L, Seager MA, Wittmann M, Jacobson M, Bickel D, Burno M, Jones K, Graufelds VK, Xu G, Pearson M, et al. (2009) Selective activation of the $M_{1}$ muscarinic acetylcholine receptor achieved by allosteric potentiation [published correction appears in Proc Natl Acad Sci USA (2009) 106:18040]. Proc Natl Acad Sci USA 106: 15950-15955.

Mistry SN, Jörg M, Lim H, Vinh NB, Sexton PM, Capuano B, Christopoulos A, Lane JR, and Scammells PJ (2016) 4-Phenylpyridin-2-one derivatives: a novel class of positive allosteric modulator of the $\mathrm{M}_{1}$ muscarinic acetylcholine receptor. $J$ Med Chem 59:388-409.

Motulsky HJ and Mahan LC (1984) The kinetics of competitive radioligand binding predicted by the law of mass action. Mol Pharmacol 25:1-9.

Paton WD and Rang HP (1965) The uptake of atropine and related drugs by intestinal smooth muscle of the guinea-pig in relation to acetylcholine receptors. Proc $R$ Soc Lond B Biol Sci 163:1-44.

Price MR, Baillie GL, Thomas A, Stevenson LA, Easson M, Goodwin R, McLean A McIntosh L, Goodwin G, Walker G, et al. (2005) Allosteric modulation of the cannabinoid $\mathrm{CB}_{1}$ receptor. Mol Pharmacol 68:1484-1495.

Samama P, Cotecchia S, Costa T, and Lefkowitz RJ (1993) A mutation-induced activated state of the $\beta_{2}$-adrenergic receptor. Extending the ternary complex model. $J$ Biol Chem 268:4625-4636.

Stahl E, Elmslie G, and Ellis J (2011) Allosteric modulation of the $\mathrm{M}_{3}$ muscarinic receptor by amiodarone and $N$-ethylamiodarone: application of the four-ligand allosteric two-state model. Mol Pharmacol 80:378-388.

Stockton JM, Birdsall NJ, Burgen AS, and Hulme EC (1983) Modification of the binding properties of muscarinic receptors by gallamine. Mol Pharmacol 23: 551-557.

Trinquet E, Bouhelal R, and Dietz M (2011) Monitoring Gq-coupled receptor response through inositol phosphate quantification with the IP-One assay. Expert Opin Drug Discov 6:981-994.

Trinquet E, Fink M, Bazin H, Grillet F, Maurin F, Bourrier E, Ansanay H, Leroy C, Michaud A, Durroux T, et al. (2006) D-myo-inositol 1-phosphate as a surrogate of D-myo-inositol 1,4,5-tris phosphate to monitor $\mathrm{G}$ protein-coupled receptor activation. Anal Biochem 358:126-135.

Unett DJ, Gatlin J, Anthony TL, Buzard DJ, Chang S, Chen C, Chen X, Dang HT, Frazer J, Le MK, et al. (2013) Kinetics of $5-\mathrm{HT}_{2 \mathrm{~B}}$ receptor signaling: profound agonist-dependent effects on signaling onset and duration. J Pharmacol Exp Ther 347:645-659.

Watt ML, Schober DA, Hitchcock S, Liu B, Chesterfield AK, McKinzie D, and Felder CC (2011) Pharmacological characterization of LY593093, an M1 muscarinic acetylcholine receptor-selective partial orthosteric agonist. J Pharmacol Exp Ther 338:622-632.

Wilder-Smith CH, Ernst T, Gennoni M, Zeyen B, Halter F, and Merki HS (1990) Tolerance to oral $\mathrm{H}_{2}$-receptor antagonists. Dig Dis Sci 35:976-983.

Address correspondence to: Dr. Terry Kenakin, Department of Pharmacology, University of North Carolina School of Medicine, 120 Mason Farm Road, Room 4042, Genetic Medicine Building, CB 7365, Chapel Hill, NC 27599-7365. E-mail: kenakin@email.unc.edu 